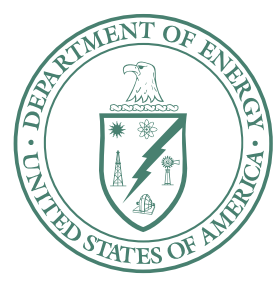

U.S. Department of Energy

Idaho Operations Office

\title{
ICDF Complex Waste Profile and Verification Sample Guidance
}

October 2006 
DOE/NE-ID-11175

Revision 2

Project No. 23350

\section{ICDF Complex Waste Profile and Verification Sample Guidance}

October 2006

Prepared for the 


\begin{abstract}
This guidance document will assist waste generators who characterize waste streams destined for disposal at the Idaho Comprehensive Environmental Response, Compensation, and Liability Act (CERCLA) Disposal Facility (ICDF) Complex. The purpose of this document is to develop a conservative but appropriate way to (1) characterize waste for entry into the ICDF; (2) ensure compliance with the waste acceptance criteria; and (3) facilitate disposal at the ICDF landfill or evaporation pond. In addition, this document will establish the waste verification process used by ICDF personnel to ensure that untreated waste meets applicable ICDF acceptance limits.
\end{abstract}




\section{CONTENTS}

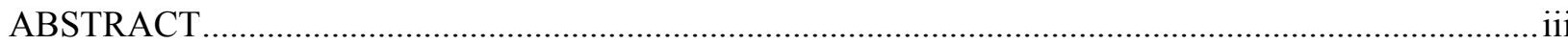

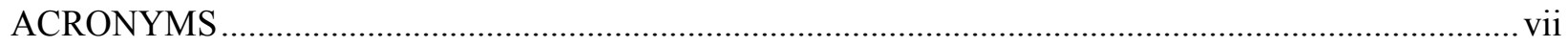

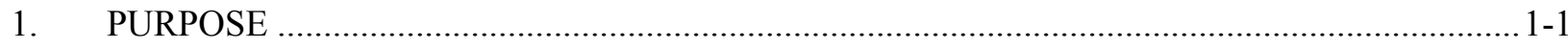

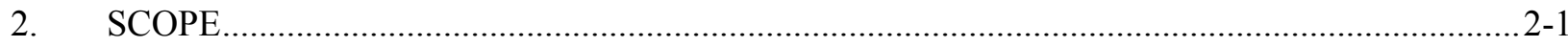

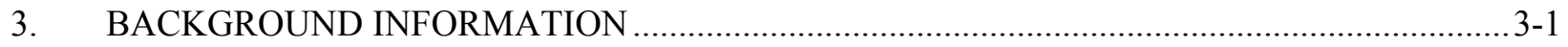

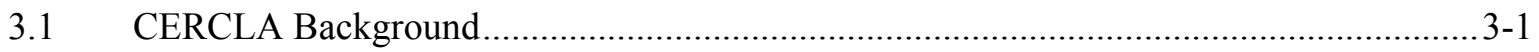

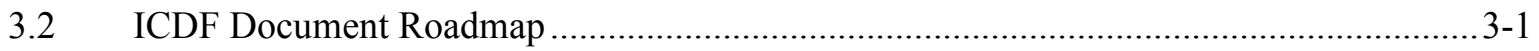

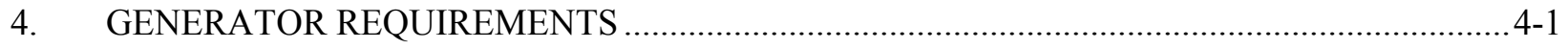

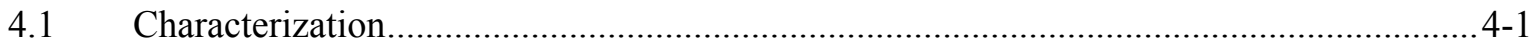

4.1.1 Waste Generator Sampling and Analysis Plans .......................................... 4-2

4.1.2 Quality Assurance Requirements/Data Quality Objectives ............................4-2

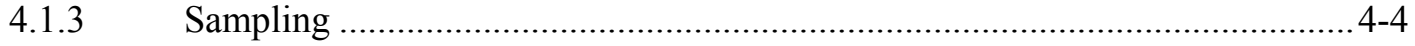

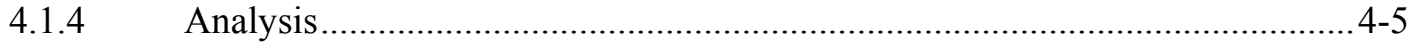

4.1.5 Acceptable Knowledge Requirements for Nonbulk Soil Waste ....................... 4-5

4.1.6 Land Disposal Restriction Characterization Requirements.............................. 4-7

4.1.7 Exceptions to Physical and Chemical Characterization Requirements .............4-7

4.1.8 Radiological Characterization ................................................................. 4-8

4.2 Integrated Waste Tracking System Material Profile ................................................... 4-11

5. ICDF COMPLEX WASTE ACCEPTANCE AND VERIFICATION PROCESS .......................5-1

$5.1 \quad$ ICDF Waste Profile Review Process ......................................................................... 5-1

5.1.1 Generator Waste Profile and Data Package Review ..................................... 5-2

5.1.2 Waste Acceptance Criteria Review Process ................................................... 5-2

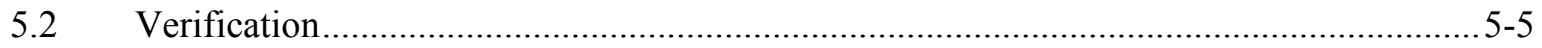

5.2.1 Verification Requirements for Waste Area Group 3 Water and

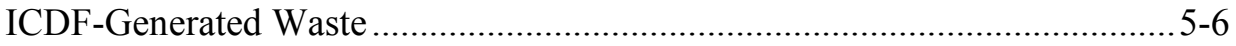

5.2.2 Verification Requirements for Debris Waste …......................................... 5-7

5.2.3 Verification Requirements for Soil Waste .................................................. 5-8

5.2.4 Verification Requirements for Liquid Waste Managed at the ICDF Evaporation Ponds .................................................................................. 5-9

5.2.5 Assessment of Verification Results........................................................... 5-9 


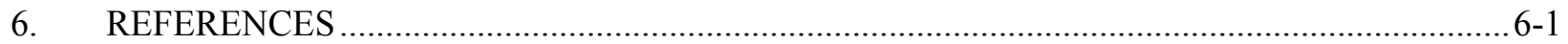

Appendix A—Waste Sampling, Analysis, and Data Quality Management Guidance ........................... A-1

Appendix B - Additional Waste Verification Sampling Guidance for Select Waste Streams ................ B-1

\section{TABLES}

5-1. Acceptance requirements for IDAPA and NESHAP key parameters in soil waste .......................5-3 


\section{ACRONYMS}

ALARA as low as reasonably achievable

AOC area of contamination

ARAR applicable or relevant and appropriate requirement

CERCLA Comprehensive Environmental Response, Compensation, and Liability Act

CFA Central Facilities Area

CFR Code of Federal Regulations

CG concentration guideline

COC contaminant of concern

DOE U.S. Department of Energy

DOT Department of Transportation

DQO data quality objective

EDF Engineering Design File

$\mathrm{EE} / \mathrm{CA} \quad$ engineering evaluation/cost analysis

EPA U.S. Environmental Protection Agency

EQL estimated quantitation limit

GC gas chromatography

GC/MS gas chromatography/mass spectrometry

HWMA Hazardous Waste Management Act

ICDF Idaho CERCLA Disposal Facility

ICP Idaho Cleanup Project

ID identification

IDAPA Idaho Administrative Procedures Act

INL Idaho National Laboratory

INTEC Idaho Nuclear Technology and Engineering Center

IWTS Integrated Waste Tracking System 


\begin{tabular}{|c|c|}
\hline LDR & land disposal restriction \\
\hline MDL & method detection limit \\
\hline NESHAP & National Emission Standards for Hazardous Air Pollutants \\
\hline NRC & U.S. Nuclear Regulatory Commission \\
\hline O\&M & operations and maintenance \\
\hline $\mathrm{OU}$ & operable unit \\
\hline PCB & polychlorinated biphenyl \\
\hline PLN & Plan \\
\hline QAPjP & Quality Assurance Project Plan \\
\hline RAWP & Remedial Action Work Plan \\
\hline RCRA & Resource Conservation and Recovery Act \\
\hline $\mathrm{RI} / \mathrm{FS}$ & remedial investigation/feasibility study \\
\hline ROD & Record of Decision \\
\hline SAM & Sample and Analysis Management \\
\hline SAP & Sampling and Analysis Plan \\
\hline SOW & Statement of Work \\
\hline SSSTF & Staging, Storage, Sizing, and Treatment Facility \\
\hline SVOC & semivolatile organic compound \\
\hline TCLP & toxicity characteristic leaching procedure \\
\hline TOS & Task Order Statement of Work \\
\hline TRU & transuranic \\
\hline USC & United States Code \\
\hline VOC & volatile organic compound \\
\hline WAC & Waste Acceptance Criteria \\
\hline WAG & waste area group \\
\hline $\mathrm{XRF}$ & $\mathrm{x}$-ray fluorescence \\
\hline
\end{tabular}




\section{ICDF Complex Waste Profile and Verification Sample Guidance}

\section{PURPOSE}

The purpose of this document is to define (1) the characterization requirements that waste generators must meet when preparing waste profiles for waste acceptance into the Idaho Comprehensive Environmental Response, Compensation, and Liability Act (CERCLA) Disposal Facility (ICDF) Complex and (2) the waste acceptance and verification processes used by ICDF Complex personnel when evaluating waste for acceptance into the facility.

The ICDF Complex Waste Acceptance Criteria document (DOE/ID-10881 [DOE-ID 2006a]) identifies the waste acceptance criteria (WAC) and limits imposed on waste being shipped to the ICDF Complex and its related units (e.g., treatment, landfill, and evaporation pond) for disposal. This document provides a roadmap to properly characterize and verify waste streams destined for the ICDF Complex, based on the ICDF Complex WAC (DOE/ID-10881 [DOE-ID 2006a] and the "Waste Tracking Plan for the Idaho CERCLA Disposal Facility Complex" (PLN-914).

The waste acceptance process outlined in these documents has been established to ensure that waste is accepted, managed, and disposed of in a manner within the operational limits of the ICDF Complex, including CERCLA (42 USC § 9601 et seq.) and those substantive provisions of other environmental statutes and regulations that have been designated as applicable or relevant and appropriate requirements (ARARs) for the ICDF, CERCLA Records of Decision and Action Memoranda, Department of Energy (DOE) Orders, Sampling and Analysis Plans (SAPs), and other applicable requirements.

Only waste that is generated through the performance of Idaho National Laboratory (INL) CERCLA response actions will be accepted for disposal at the ICDF Complex. The ICDF Complex is located near the southwest corner of the Idaho Nuclear Technology and Engineering Center (INTEC) and immediately west of the existing percolation ponds. The area of the ICDF Complex, including a buffer zone, covers approximately 40 acres with a landfill disposal capacity of approximately $510,000 \mathrm{yd}^{3}$ (DOE/ID-10660 [DOE-ID 1999]).

All waste destined for the ICDF Complex must meet the specific ICDF Complex WAC (DOE/ID-10881 [DOE-ID 2006a]) (e.g., landfill, evaporation pond, etc.), depending on the ultimate disposition of the waste. Section 4.0 of this document describes the requirements for successfully developing a waste profile for approval at the ICDF Complex. 
1-2 


\section{SCOPE}

This document defines the requirements for thorough, accurate, and complete waste characterization; the process for waste profile development, and waste acceptance activities. The responsibilities to implement the scope of this document are as follows:

- Waste Generators: Perform physical sampling and analysis activities to allow completion of waste profiles. Generators shall conduct waste characterization activities in accordance with Data Quality Objectives (DQOs) that, in addition to addressing remediation goals, assess whether or not the maximum concentration of the waste is below the concentration guideline (CG) per the ICDF Complex WAC (DOE/ID-10881 [DOE-ID 2006a]).

Section 4 of this document provides guidance for waste generators to follow when characterizing waste to ensure these standards are met. Section 4 applies to all generators of CERCLA response action waste within the INL that plan to dispose of those waste streams at the ICDF Complex. Generators of CERCLA response action waste destined for disposal at the ICDF Complex must be familiar with the guidelines in this document as well as the ICDF Complex WAC document (DOE/ID-10881 [DOE-ID 2006a]).

- ICDF Waste Acceptance Personnel: (1) Conduct a review of the waste profile and supporting waste characterization documentation provided by the generators for adequacy and to determine whether the proposed waste stream is within established WAC limits for the designated ICDF unit (e.g., landfill, evaporation pond, and the Staging, Storage, Sizing, and Treatment Facility [SSSTF]); and (2) perform waste verification prior to final acceptance at the ICDF Complex using qualitative fingerprint methods to ensure the waste received matches the information provided on applicable waste profile submitted by the waste generator.

Section 5 of this document describes the waste profile review and verification activities conducted by ICDF personnel when evaluating waste streams for acceptance to the ICDF Complex. 
2-2 


\section{BACKGROUND INFORMATION}

This section describes (a) CERCLA requirements under which the ICDF Complex operates and (b) important operational documents. It also explains the relationship between ICDF Complex documents and the generator's CERCLA documentation. The generator must be familiar with the regulatory and operational structure of the ICDF Complex. Generator waste characterization requirements are addressed in Section 4 of this document.

\subsection{CERCLA Background}

The U.S. Department of Energy Idaho Operations Office authorized a remedial design/remedial action for INTEC to satisfy the requirements of the Waste Area Group (WAG) 3, Operable Unit (OU) 3-13, Record of Decision (ROD) (DOE/ID-10660 [DOE-ID 1999]). The ROD selected "Removal and On-Site Disposal" as the remedy for OU 3-13, Group 3, "Other Surface Soils." To support this remedy, as well as other response actions within the INL Site, the ROD requires that an on-Site landfill be constructed to receive CERCLA response action waste generated within the INL Site. The ICDF Complex is the on-Site facility designed and constructed to implement the ROD requirements.

The ICDF Complex is the consolidation point for CERCLA-generated waste within the INL Site boundaries. In addition to receiving WAG 3 waste, the landfill also will be able to receive CERCLA-generated waste from outside WAG 3 that meets the land disposal restriction (LDR) requirements in accordance with specific landfill WAC (DOE/ID-10881 [DOE-ID 2006a]). (Waste generated within the WAG 3 area of contamination [AOC] that has not triggered placement is not required to meet LDR criteria.) The ICDF landfill meets the substantive requirements of Resource Conservation and Recovery Act (RCRA) Subtitle C (42 USC § 6921 et seq.), Idaho Hazardous Waste Management Act (HWMA 1983), DOE Order 435.1, and Toxic Substances Control Act polychlorinated biphenyl (PCB) landfill design and construction requirements (15 USC $\S 2601$ et seq.).

The OU 3-13 ROD outlines applicable or relevant and appropriate requirements (ARARs) for the operation of the ICDF Complex. Compliance with the ARARs and design standards for the liner establish the operational limitations of the ICDF Complex. The INEEL CERCLA Disposal Facility Complex Remedial Action Work Plan (RAWP) (DOE/ID-10984 [DOE-ID 2003a]) and the ICDF Complex Operations and Maintenance Plan (O\&M Plan) (DOE/ID-11000 [DOE-ID 2006b]) provide additional information about operational requirements at the ICDF Complex.

\subsection{ICDF Document Roadmap}

The ICDF Complex only accepts waste streams generated by CERCLA activities

(i.e., investigation, Notice of Disturbance, removal action, or remedial action) within the INL Site. Generators of CERCLA removal and remediation waste destined for disposal at the ICDF Complex must be familiar with the guidelines in this document, as well as ICDF Complex operations described in the ICDF Complex RAWP (DOE/ID-10984 [DOE-ID 2003a]) and the ICDF O\&M Plan (DOE/ID-11000 [DOE-ID 2006b]). These documents were developed to ensure compliance with the OU 3-13 ROD (DOE/ID-10660 [DOE-ID 1999]) and the protection of human health and the environment. Additional documents such as the ICDF Complex Waste Acceptance Criteria (DOE/ID-10881 [DOE-ID 2006a]) were developed to ensure that the operational limits of the ICDF Complex are not exceeded.

ICDF Complex operational limits have been established to meet the requirements of the ROD and be protective of human health and the environment. The generator must be aware of ICDF Complex operational limits and will be required to characterize, treat, and ship waste in compliance with those 
limits. An understanding of these requirements is vital to the preparation of waste profiles that facilitate waste acceptance into the ICDF Complex. They are described in detail in the following documents:

- $\quad$ ICDF Complex WAC: The ICDF Complex Waste Acceptance Criteria (DOE/ID-10881 [DOE-ID 2006a]) identifies the requirements that apply to all waste streams entering the ICDF Complex. This document integrates all waste acceptance procedures at the ICDF Complex, including the ICDF SSSTF. The ICDF Complex WAC document delineates ICDF landfill and evaporation pond WAC, specifying the chemical and radiological requirements for the disposal of solid waste (e.g., soil and debris) in the ICDF landfill and specifying the chemical and radiological requirements for disposal of aqueous waste in the ICDF evaporation pond. Primary elements of the ICDF Complex WAC document (DOE/ID-10881 [DOE-ID 2006a] include the following:

- $\quad$ Responsibilities (Section 1.4)

- ICDF waste stream profile process, including waste requiring special consideration (Section 2)

- General waste acceptance criteria, including prohibited waste, physical and chemical criteria, and radiological criteria (Section 4)

- Waste acceptance criteria for the ICDF landfill (Section 5)

- Waste acceptance criteria for the ICDF evaporation pond (Section 6)

- Waste acceptance criteria for the Staging, Storage, Sizing and Treatment Facility (Section 7).

- $\quad$ Waste Tracking Requirements: "The Waste Tracking Plan for the ICDF Complex" (PLN-914) describes how waste will be tracked at the ICDF Complex. Section 2 of the Waste Tracking Plan describes the Integrated Waste Tracking System (IWTS) waste profiling process in detail. 


\section{GENERATOR REQUIREMENTS}

Generators of waste destined for the ICDF Complex are solely responsible for performing waste characterization to develop waste profiles that accurately quantify each constituent present in the waste stream. In addition, waste generators have general responsibilities regarding waste characterization under their CERCLA documentation, which are not superseded by this document:

- $\quad$ Records of Decision

- $\quad$ Remedial Action Work Plans

- $\quad$ ICDF Complex WAC document (DOE/ID-10881 [DOE-ID 2006a])

- $\quad$ ICDF Complex Waste Tracking Plan (PLN-914).

Acceptance of a waste stream at the ICDF Complex is contingent upon effective implementation of these responsibilities.

\subsection{Characterization}

Waste characterization will be performed to determine the physical, chemical, and radiological characteristics of the waste to properly designate and manage waste in accordance with the ICDF Complex WAC (DOE/ID-10881 [DOE-ID 2006a]). These waste characteristics will be recorded on a waste profile. Characterization for all waste submitted for acceptance into the ICDF Complex is the sole responsibility of the waste generator and must be completed before the waste profile is submitted.

The waste generator's waste characterization shall reflect validated analytical data rendered from statistically based SAPs that were properly executed. When appropriate, the application of defensible process knowledge will be accepted. Section 4.1.1 defines the waste generator's obligation to develop and implement SAPs for each waste stream being characterized. Section 4.1.3 defines the appropriate sampling methodology to be addressed in the SAP for use when characterizing waste. Section 4.1.4 provides appropriate analytical techniques to be used, including a discussion on when the use of process knowledge is suitable for performing waste characterization.

Before initiating waste characterization activities, waste generators unfamiliar with the ICDF process shall contact the ICDF Complex for oversight and guidance in developing the SAPs and waste profiles. ICDF Complex personnel will be available throughout the waste generator's characterization activities and will communicate with the waste generators during the profile review and approval process to ensure all ICDF characterization requirements are met prior to waste acceptance.

Many of the waste streams destined for management at the ICDF Complex have already been characterized to some degree as part of the remedial investigation/feasibility study (RI/FS), engineering evaluation/cost analysis (EE/CA), or other CERCLA planning and scoping activities. These data should be evaluated to determine if they are of adequate quantity and quality to meet the waste characterization DQOs. In some instances, it is anticipated that adequate data will exist to allow approval of a waste profile without the need to perform any additional sampling and analysis. In many other instances, it is presumed that the waste generator will be required to perform additional sampling and analysis to supplement or replace the initial characterization information in order to meet the quality requirements described in this document. Appendix A contains detailed supporting guidance regarding sample collection methods, sample control, project quality objectives, analytical methods, and data management that waste generators should use when developing sampling and analysis strategies for waste streams destined for the ICDF Complex. 


\subsubsection{Waste Generator Sampling and Analysis Plans}

Each waste generator is responsible for developing a SAP prior to submitting the waste profile. The SAP must be prepared to incorporate the DQOs and sampling and analysis requirements defined in Sections 4.1.2, 4.1.3, and 4.1.4 of this document respectively. The SAP is the primary support document for the waste profile. The SAP developed for the waste generator's CERCLA activities should (1) describe the sampling protocol; (2) identify requisite analysis, analytical methods, and data validation protocol; and (3) describe the process for characterizing the waste, including what parameters will be estimated (e.g., mean, median, and percentile) to provide the logic used to derive the needed number of samples. The physical state, material waste composition, and specific item description also shall be addressed in the characterization process.

Existing SAPs will be reviewed and modified as necessary using DQOs applicable for waste characterization.

The SAP describes the methods to be used to ensure that information is accurately recorded for transportation, storage, and disposal. As part of the SAP, each waste generator must develop a methodology to accurately document the percent by volume of each item type in the waste. Applicable analytical methods used to determine physical, radiological, and chemical characteristics of each waste stream shall be addressed in the SAP. A guideline published by the U.S. Environmental Protection Agency (EPA) updates technical information for sampling and analysis regimes (EPA 2002). The waste generator should review this document, along with relevant Idaho Cleanup Project (ICP) guidance, before developing a SAP.

The SAP is the key document the waste generator uses to ensure that waste is accurately characterized, and it provides the basis for objectively demonstrating compliance with the ICDF Complex WAC (DOE/ID-10881 [DOE-ID 2006a]). The waste generators shall incorporate appropriate DQOs into the SAP to assess whether or not the maximum concentration in the waste is below the concentration guideline. Compliance with the SAP is assumed when a waste profile is presented for approval at the ICDF Complex.

\subsubsection{Quality Assurance Requirements/Data Quality Objectives}

The Quality Assurance Project Plan for Waste Area Groups 1, 2, 3, 4, 5, 6, 7, 10, and Removal Actions (DOE-ID-10587 [2006c]), referred to as the QAPjP, provides quality assurance/quality control requirements for numerous projects at INL, including ICP CERCLA and removal action sampling activities. This document includes guidance on the number and type of quality control samples required for various project sampling activities, along with referencing standard analytical laboratory methods used for analysis and requirements for sample holding times and preservation. Waste generators must conduct waste characterization sampling activities/events in accordance with the requirements of the QAPjP to ensure the data generated are accurate and defensible. The DQOs defined in Sections 4.1.2.1 through 4.1.2.7 below apply to untreated bulk soil waste being submitted to the ICDF for disposal and does not supersede any other DQOs required of the waste generator to meet characterization requirements.

4.1.2.1 State the Problem. The problem for the characterization of soil waste is to ensure key parameters that could impact ICDF operations do not exceed the concentration guideline prior to disposal. 
4.1.2.2 Identify the Decision. The following is the principal study question to be addressed for the waste characterization of soil waste:

- Is the maximum concentration in the waste destined for the ICDF below the applicable concentration guidelines?

The alternative actions that will be taken based on the data collected are:

- If the waste generator's 22 sample results are below the concentration guidelines, then submit the waste profile to ICDF for acceptance.

- If the waste generator's sample results indicate constituent concentrations above the WAC concentration guidelines, then the data will be used by ICDF personnel to determine the mass for the constituents. If said mass, when added to the landfill running constituent inventory, will result in a running constituent inventory below the WAC concentration guideline, the waste will be approved. statement:

Combining the principal study question and the alternative actions results in the following decision

- Determine whether the maximum concentration in the waste is below applicable concentration guidelines to ascertain if waste is acceptable for disposal at the ICDF landfill or if an estimate of constituent mass is necessary.

4.1.2.3 Identify the Inputs to the Decision. The following will be required to resolve the decision statement associated with the waste characterization:

- $\quad$ Sample data from 22 samples

- $\quad$ List of key parameters for the waste stream of interest

- $\quad$ Completed Material Profile addressing key parameters found in the waste stream

- $\quad$ Assessment of the characterization data quality to ensure it meets the characterization DQOs (i.e., holding times, analysis methods, analytical results, number of samples, etc.).

4.1.2.4 Define the Study Boundaries. The spatial boundaries of concern for this study are confined to the soil waste stream. Decisions will be made on a waste stream basis. A waste stream is defined to be the volume of waste generated during the specific cleanup activities. The waste in question for this study is limited to soil waste destined for direct disposal at the landfill.

4.1.2.5 Develop Decision Rules. A decision rule defines the conditions that would cause the decision-makers to choose between the alternative actions, and it typically takes the form of an "If...then" statement describing the action to take, if one or more conditions are met. This decision rule specifies the statistic of interest and the action level. To assess whether the maximum concentration of the waste is below the CG, the waste generator must take enough samples to be $90 \%$ confident that $90 \%$ of their waste is below the applicable concentration guidelines. This would require the waste generator to take 22 samples for each $5,000 \mathrm{yd}^{3}$ of bulk soil, enough to estimate an upper tolerance limit (UTL) on an upper percentile. The decision rules are as follows:

- If the waste generator's 22 characterization sample results are below the concentration guidelines, then accept the waste. 
- If the waste generator's 22 characterization sample results are above the WAC concentration guideline, then the characterization data will be used by ICDF personnel to determine the mass of the constituents. If said mass, when added to the landfill running constituent inventory, will result in a running constituent inventory below the WAC concentration guideline, then the waste stream will be approved.

4.1.2.6 Specify Limits on the Decisions. The Type 1 error is making the incorrect decision and saying that for any key parameter less than $10 \%$ of the waste exceeds the $\mathrm{CG}$, when in fact more than $10 \%$ of the waste exceeds the CG. The limit on the probability of this error is specified to be $10 \%$. The risk from a Type 1 error is (1) possible exceedance of the concentration guideline, (2) inaccurate calculation of the landfill mass limit, or (3) possible procedural violation.

The Type 2 error is making the incorrect decision and saying that for any key parameter more than $90 \%$ of the waste exceeds the CG, when in fact less than $90 \%$ of the waste exceeds the CG. This is not possible with this approach; therefore, no limit on the probability of this error is specified.

4.1.2.7 Optimize the Design for Obtaining Data. The goal is to ensure that the maximum concentration of key parameters in the soil waste that is accepted at the landfill is below the concentration guideline.

To assess whether the maximum concentration in the waste is below the CG, an upper tolerance limit approach will be used. The parameter of interest is the 90th percentile, and the specified Type 1 error is $10 \%$.

\subsubsection{Sampling}

Waste generators are responsible for developing sampling plans that ensure a sufficient number of samples are taken resulting in the confidence levels necessary to provide an accurate representation of the waste stream to be shipped to the ICDF Complex. The sampling methodology used is dependent on the waste source and type, as specific DQOs have been developed for bulk soils waste versus other waste (i.e., debris, etc.) that may be shipped to the ICDF.

4.1.3.1 Bulk Soil Sampling. When conducting sampling of bulk soils, the maximum lot size for determining the number of soil samples to be taken is $5,000 \mathrm{yd}^{3}$. An additional 22 samples must be taken for each $5,000 \mathrm{yd}^{3}$ of bulk soil in a waste stream. Waste streams that are less than $500 \mathrm{yd}^{3}$ are not considered bulk soils. For soil streams less than $500 \mathrm{yd}^{3}$, divide the total yardage by 25 and the result will be the required number of samples. A minimum of two samples must be taken for all lots less than $50 \mathrm{yd}^{3}$ ). The DQOs defined in Section 4.1 .2 of this document that establish the minimum number of samples must be taken into account. The following considerations shall be taken into account when conducting sampling of bulk soils:

- A grid should be established over the location of response action to ensure that samples have been taken that are representative of hazardous constituents in the entire mass being managed through the response action.

- $\quad$ Existing data may be used if samples were taken and results obtained through comparable analytical methods. These issues are important for combining data. Pre-existing data will be evaluated to be consistent with the characterization DQOs.

- It is recommended that the sampling be conducted while the soil is still "in situ" rather than after the waste has been containerized. 
- In cases where the soils have known "hot spots" of significant chemical or radiological contamination, it is highly desirable to characterize and profile the areas of high contamination as a separate waste stream from the surrounding areas.

4.1.3.2 Sampling of Other Containerized Soil. The following considerations shall be taken into account when determining the sampling scheme for a given waste stream to ensure DQOs are achieved:

- $\quad$ Sample schemes are dependent on the waste stream and matrix. Samples may be taken either at random, as determined by the statistical method used, or via biased sampling.

- $\quad$ The number of samples taken shall be based on established statistical methods. This requires a properly designed and executed sampling event that renders sufficient samples to represent the universe of waste being profiled.

- $\quad$ Existing data may be used if samples were taken and results obtained through comparable analytical methods. These issues are important for combining data. Pre-existing data will be evaluated to be consistent with the characterization DQOs.

\subsubsection{Analysis}

ICDF Complex operations are limited by several key parameters (e.g., landfill contaminants of concern [COCs], LDRs, and transuranic [TRU] radionuclides). Characterization must thoroughly quantify all of the key parameters in order for the waste to be evaluated to ensure it can be compliantly accepted at the ICDF Complex. The requisite constituents and key parameters necessary to be evaluated/analyzed are defined in the ICDF Complex WAC (DOE/ID-10881 [DOE-ID 2006a]). The waste generators must conduct analysis for those constituents reasonably expected to be present in the waste. Waste characterization can be performed by using detailed sampling and analysis or through the application of waste knowledge (e.g., process knowledge or previous sampling events, or by a combination of the two) (EPA 1999). The use of acceptable knowledge is limited to nonbulk soil waste and cannot be used for the characterization of I-129 concentrations. Sampling and analysis must be used for bulk soil waste and to determine I-129 levels in all waste streams suspected of having that constituent present.

Generally, SW-846 test methods (EPA 1999) or other methods with proper quality assurance and quality control standards provide sufficient verifiable information to prepare a suitable waste profile. Section 4.2 of the ICDF Complex WAC (DOE/ID-10881 [DOE-ID 2006a]) describes the requirements for physical and chemical characterization. Radiological characterization is discussed in detail in Section 4.3 of the ICDF Complex WAC. In some cases, characterization results can be obtained through the use of documented process knowledge in lieu of detailed physical sampling and chemical analysis as described in Section 4.1.5 below.

\subsubsection{Acceptable Knowledge Requirements for Nonbulk Soil Waste}

Due to the nature and source of many nonbulk soil waste types, the use of defensible acceptable process knowledge may, in some cases, be used to provide adequate characterization of the waste. This section describes types of information that can be used for physical/chemical characterization including data from waste analysis and knowledge of the materials and/or processes that led initially to the creation of, and later removal or remediation of, the specific waste.

When a waste designation is based solely on process knowledge, the generating site must ensure that the chemical, physical, and radiological properties of the waste are adequately determined. The designation must be accomplished and documented with sufficient accuracy to ensure that subsequent 
treatment, storage, or disposal of the waste will be protective of human health and the environment. The logic used to make the designation must be documented. The technical basis, including documented historical information, procedures, practices, and information gained from interviews shall be documented. Any assigned listed waste codes apply to the waste stream throughout the disposition process unless a "No Longer Contained In" determination has been made by applicable authority.

The minimum level of acceptable knowledge must include (1) designation data where the constituents causing a listed waste code to be assigned are quantified and (2) data that address acceptance criteria necessary for proper management of the waste. The generator should be aware of waste verification procedures outlined in Section 5.0 of this document. Failure to meet the WAC limits will result in rejection of the waste stream and/or shipments.

Analytical data and/or knowledge of the waste must be sufficient to determine whether the waste is of the type regulated as hazardous under 40 CFR 261, "Identification and Listing of Hazardous Waste," or 40 CFR 761, "Polychlorinated Biphenyls (PCBs) Manufacturing, Processing, Distribution in Commerce, and Use Prohibitions," and to assign correct hazardous waste codes (when applicable). When the available information does not qualify as acceptable knowledge, or is not sufficient to characterize a waste for management, the sampling and testing methods commonly used to make a hazard determination may be required. The presence or absence of hazardous constituents by chemical analysis alone does not indicate that a listed waste is present. The only way a listed waste code can be assigned to a waste stream is through process knowledge.

In cases where constituents that could cause a waste to be listed are present in a process, but are not expected to be in the waste in concentrations causing the waste to be above LDRs (e.g., those wastes that have been generated outside the WAG 3 AOC or that have triggered placement), sampling and analysis must be performed to demonstrate that the constituents are below regulatory limits for land disposal. This requirement can be met through previous investigations such as RI/FSs or other CERCLA investigations.

Listed waste must be designated based on process knowledge. Other waste stream designations may be based on process knowledge and/or analytical data. The generating CERCLA project will perform a review to determine whether a listed waste source is present at the location of the response action. The listed waste review will rely on readily available documents gathered as a part of the standard CERCLA removal site evaluation or RI/FS. For CERCLA OUs from which listed waste sources are reasonably expected, standard operator interviews should be augmented and documented as necessary to ask questions specifically aimed at identification of potential sources.

4.1.5.1 Types of Acceptable Knowledge. Acceptable knowledge requirements can be met using one or more of the following:

- Mass balance from a controlled process that has a specified output for a specified input including time of generation

- Material Safety Data Sheets on unused chemical products

- Labeling on original containers of unused chemical products or materials

- Analytical data on the waste or a waste from a similar process, including sufficient information to demonstrate that the two wastes are essentially the same

- Test data from a similar process, including sufficient information to document that the waste is essentially the same as that from a similar process. 
In addition, acceptable knowledge requirements can be met through the use of a combination of analytical data or screening results and one or more of the following:

- Documented interview information

- Logbooks

- $\quad$ Procurement records

- Qualified analytical data

- $\quad$ Radiation work packages

- $\quad$ Procedures and/or methods

- $\quad$ Process flow charts

- Inventory sheets

- Vendor information

- $\quad$ Mass balance from an uncontrolled process (e.g., spill cleanup)

- $\quad$ Mass balance from a process with variable inputs and outputs (e.g., washing/cleaning methods).

If the information is sufficient to quantify waste constituents and characteristics, as required by the regulations and facility-specific acceptance criteria, the information is considered acceptable knowledge. These types of information will require a separate concurrence by the ICDF Complex waste specialist prior to the waste being accepted at the ICDF Complex.

\subsubsection{Land Disposal Restriction Characterization Requirements}

For hazardous waste (as defined in 40 CFR 261) that has been generated outside the WAG 3 AOC and hazardous waste that was generated inside the WAG 3 AOC and has triggered placement, waste characterization must be sufficient to establish whether the waste is a restricted waste under the LDR provisions of 40 CFR 268, "Land Disposal Restrictions," or the alternative LDR treatment standards for contaminated soil under 40 CFR 268.49, "Alternative LDR Treatment Standards for Contaminated Soil." If either of those LDR provisions apply, the applicable treatment standard(s) for that waste must be determined. Data from a CERCLA RI/FS can be utilized for this demonstration if the sample is a representative sample as defined in 40 CFR 260.10, "Definitions-Hazardous Waste Management System: General," and the appropriate parameters analyzed.

All waste generators who generate waste streams originating outside the WAG 3 AOC must comply with LDRs prior to acceptance of the waste stream in the ICDF Complex, or must arrange for the ICDF to treat the waste to meet LDRs before disposal. Note, at the present time, the ICDF treatment capabilities are limited to soil stabilization and debris microencapsulation.

\subsubsection{Exceptions to Physical and Chemical Characterization Requirements}

The following exceptions can be made to the physical/chemical characterization requirements stated previously:

- Hazardous debris managed in accordance with the alternative treatment standards for hazardous debris (40 CFR 268.45, "Treatment Standards for Hazardous Debris") does not require sampling and analysis for adequate physical/chemical characterization 
- Hazardous debris that will not be treated (e.g., debris from remediation or removal activities inside the OU 3-13 AOC) but contains other media such as sludge or soils must be characterized

- Waste that cannot be fully characterized in accordance with the requirements stated previously may be characterized by an alternative management path negotiated with the ICDF Complex management and the Idaho Department of Environmental Quality (DEQ) and EPA (e.g., if there are unique chemical or radiological hazards posing risks to workers that prevent full characterization of the waste).

\subsubsection{Radiological Characterization}

The major radionuclides (as defined in the ICDF Complex WAC [DOE/ID-10881]) in the waste and the concentration of each major radionuclide must be established to properly classify and manage the waste in accordance with the associated radiological limits.

4.1.8.1 Identification of Major Radionuclides. For the purposes of the radiological criteria in this document, major radionuclides are defined as those radionuclides that meet any of the following conditions:

- $\quad$ Any TRU radionuclides present in the nonaqueous waste in a concentration exceeding $1 \mathrm{nCi} / \mathrm{g}$

- Any TRU radionuclides present in the aqueous waste in a concentration exceeding $1 \mathrm{nCi} / \mathrm{L}$

- Any radionuclide that accounts for more than $1 \%$ of the total radiological activity of the waste

- Any fissionable radionuclide present in the waste in a quantity exceeding 0.1 fissile gram equivalent present per container

- $\quad$ Any mobile radionuclide present in a concentration that exceeds its reporting limit.

For waste that cannot be radiologically free-released, an estimate of radiological constituents will be included in the waste profile for tracking purposes.

\subsubsection{Acceptable Knowledge and Methods for Establishing Radionuclide}

Inventories. The radionuclide inventory of a waste must be established through the use of a method or combination of methods capable of identifying and quantifying the major radionuclides present. The methods chosen must provide adequate sensitivity and accuracy to ensure that the waste meets the criteria.

A graded approach should be applied when planning radiological characterization. Using the graded approach, additional detailed analysis is applied when the concentration of radionuclides in the waste approaches one or more of the limits (e.g., longer count times or radiochemical analysis) of the ICDF Complex WAC (DOE/ID-10881 [DOE-ID 2006a]) or operational limits. Conversely, waste that measures far below these limits would not require as extensive analysis.

The following characterization methods can be used individually or in combination to establish the radionuclide inventory of the waste:

- $\quad$ Process knowledge includes documented knowledge of the radioactive materials used and the processes that contributed to the radiological content of the waste, along with historical analysis of waste and radiological contamination from the process. Process knowledge can be used to establish the suspected major radionuclides in a waste stream. In addition, process knowledge can be used to eliminate from further consideration those radionuclides not present in sufficient concentration to 
be major radionuclides, as long as the basis of this determination is documented. Process knowledge alone generally may not be sufficient to quantify the total radionuclide inventory of a waste.

- $\quad$ Direct measurement field and laboratory analysis methods, such as radiochemical analysis and surveys with field instruments, must be selected to appropriately detect and quantify the major radionuclides with adequate sensitivity and accuracy for waste classification. Analytical methods that measure gross activity (i.e., not radionuclide specific) may be used in conjunction with other methods to determine the relative concentration (scaling factors) of each suspected radionuclide and may be corroborated periodically with radionuclide-specific analysis.

- Computer modeling, applied appropriately, may be used in conjunction with other methods for radiological characterization. An individual who is knowledgeable and experienced in the use and limitations of the model must perform the modeling. The assumptions and measurements used as inputs to computer modeling must be documented. The computer software must be controlled in a manner that meets conventional quality assurance requirements. Computer models must be corroborated periodically with direct measurement methods.

- $\quad$ Scaling factors can be used to relate the concentration of a readily measured radionuclide to radionuclides that are more difficult to measure. Scaling factors must be developed from one of the previous methods and should be corroborated periodically with radionuclide-specific analysis. Other methods of radiological characterization could be used but must be clearly documented and approved by the ICDF Complex management. Documentation of the method must include a detailed description of the method, the radionuclides identifiable by the method, and a discussion of precision, accuracy, quality assurance, and quality control methods.

4.1.8.3 Determining Radionuclide Concentrations. Guidance for determining concentrations of radioactive waste is found in the U.S. Nuclear Regulatory Commission's (NRC) Issuance of Final Branch Technical Position on Concentration Averaging and Encapsulation, Revision in Part to Waste Classification Technical Position (NRC 1995). The technical position was issued for purposes of documenting the NRC's position regarding the application of averaging for purposes of determining the waste category in accordance with its promulgated regulation 10 CFR 61.55, "Waste Classification."

Radionuclide concentrations should be determined based on the volume or mass of the final waste form, as appropriate. Samples may be taken for analysis either from the final waste form or from the waste prior to processing into a final waste form. Where a liquid waste is stabilized (e.g., with grout) within a waste container, and the waste and the binder forms a solid mass within the container, the waste classification volume may be considered to be the volume of the stabilized mass. However, while the classification of stabilized liquids would be based on the volume and mass of the stabilized waste mass, the mass (or volume) of materials onto which liquids are simply adsorbed would not be included in the mass (or volume) of the waste matrix.

Shielding configurations must be considered when calculating the mass of the waste package. The mass of the packaging container and any external shielding shall not be used when determining concentrations. Shielding materials in a shielded package, where the shielding materials are not to be disposed of with the waste, are not to be considered part of the waste matrix. Shielding that is not readily removable and will be disposed of with the waste should be considered part of the waste matrix. Most waste streams (e.g., spent ion-exchange resins, filter media, solidified liquids, or contaminated dirt) may be considered to be homogeneous and therefore an integral part of the waste mass for purposes of waste classification. Trash-contaminated waste streams that are composed of a variety of miscellaneous materials may be considered homogeneous for purposes of waste classification when samples are placed 
into containers. The activity of small concentrated sources within the trash (e.g., small check sources or gauges) may be generally averaged over the trash volume.

For the purpose of waste classification of large unpackaged components (e.g., pumps and heat exchangers), the concentration of a radionuclide may be averaged over the volume of the component. Where items are placed in a container, however, and the volume of the container is at least $10 \%$ greater than the waste, the volume used for waste classification should be that of the waste and not the gross volume of the container.

Because liquids absorbed into solid media (e.g., cat box litter) can desorb under some circumstances, classification of absorbed liquids should be based on the volume and mass of the liquids prior to absorption.

Large volumes of waste that will be segregated during disposal activities are to be classified based on the separate portions rather than on the accumulated whole. This rationale is based on the assumption that segregated portions will be disposed of separately; the classification is to be based on the waste portion after any segregation has occurred.

This radioactive waste classification guidance is depicted in the following examples:

- A tank contains a radioactive heel. If the heel will not be removed but is to remain with the tank structure for disposal, then the mass of the tank structure and the heel may be added together to determine the concentration of radionuclides in the waste. The void spaces must be eliminated (e.g., crush or grout in the tank) before the waste is disposed. If the heel is to be removed separately, then the heel must be classified separately from the tank structure.

- A radioactive liquid requires disposal. The waste stream is to be treated using an immobilization medium (binder) to fix the material and make it solid. The classification of this liquid would be based on the mass of the stabilized material or on the mass of the solidified waste matrix.

- A concrete basin contains a radioactive sludge. A fixative is to be added to the sludge to stabilize any liquids. The stabilized sludge is to be removed and the basin walls scabbled to remove residue. In this case, the stabilized sludge and the scabbled material may be consolidated in order to classify the waste. The stabilized sludge and the scabbled material are of a similar nature and will be collected and disposed of as a single waste. The concrete basin is classified separately from the sludge and scabbled material. If the basin walls are not scabbled, the residue and the walls may be combined to classify the concrete waste. If the sludge and the concrete walls are segregated before disposal, the concrete and the sludge cannot be combined to classify the waste.

- A slab of concrete is being removed along with contaminated soil. There will be no attempt to segregate the soil from the concrete. The broken pieces of concrete are mixed with the removed soil as a result of the removal activity, and all the material will be disposed of together. In this case, the soil and the concrete may be classified together.

4.1.8.4 Characterization of Debris Waste Containing TRU Parameters. Waste generators characterizing debris waste containing TRU parameters must complete a waste profile. The generator must develop a detailed document that defines the process used to characterize the waste. The document will contain the activities and calculations used to determine TRU concentrations in the waste form. Refer to Section 5.2.2.2 of this document for detailed information that must be contained in the TRU waste characterization documentation. 


\subsection{Integrated Waste Tracking System Material Profile}

Each waste generator must prepare a waste profile for approval before any waste stream is shipped to the ICDF Complex using the characterization information obtained by following the guidance of Section 4.1 of this document.

The following ICDF Complex documents outline the development of a waste profile sheet:

- ICDF Complex WAC (DOE/ID-10881 [DOE-ID 2006a]), Section 3, "Waste Acceptance Process," describes the process and scheduling requirements for preparing waste profiles.

- ICDF Complex Waste Tracking Plan (PLN-914), Section 3, provides a step-by-step description of the process for preparing the waste profile, including the following:

- $\quad$ Preparation of the waste profile (Section 3.1). The waste profile describes the chemical, radiological, and physical characteristics for the waste stream, which are generally entered as maximum/minimum ranges to encompass all containers in the waste stream. Integrated Waste Tracking System (IWTS) automatically assigns the waste profile a unique identification number beginning the process of electronically tracking the waste.

- $\quad$ Preparation of the IWTS container profile (Section 3.2). The container profile documents and quantifies the chemical, radiological, and physical characteristics for that particular container. These characteristics are entered as specific values and are bounded by the maximum/minimum ranges of the associated waste profile. Supporting information specific to the individual containers, such as special handling instructions, identification of a nonstandard waste container, and documentation of physical contents verification is also provided in the container profile.

- $\quad$ Preparation of the IWTS shipment task and waste packaging and shipment requirements (Section 4). ICDF personnel create an IWTS shipment task and complete the "execute send" portion of the task. In addition, an on-Site waste tracking form must accompany the shipment to the ICDF Complex. A shipment sent without prior arrangement will be returned to the generating WAG. 


$$
\text { 4-12 }
$$




\section{ICDF COMPLEX WASTE ACCEPTANCE AND VERIFICATION PROCESS}

Acceptance of waste at the ICDF Complex consists of two phases. In the first phase, ICDF Complex personnel perform a detailed review of the waste characterization data provided by the waste generators and recorded on the waste profiles. This constitutes the first phase of the verification plan. If the waste generator data are deemed of adequate quality, and the waste stream is within applicable WAC concentration guidelines, the waste stream is approved for management at the ICDF. In the second phase, prior to final receipt and acceptance, ICDF personnel perform qualitative waste verification activities to ensure that the waste being shipped to the facility is the actual waste described on the waste profile and supporting documentation. This approach provides assurance that the waste has been sufficiently characterized by the waste generator and no discrepancies exist in each actual waste shipment.

The following presents an overview of the waste acceptance process (detailed descriptions of the waste profile review process and waste verification activities are described in Sections 5.1 and 5.2, respectively):

- $\quad$ The waste generator characterizes the waste stream pursuant to the data collection requirements identified in the OU's sampling strategy (e.g., SAP).

- $\quad$ The waste generator submits the waste profile and SAP used to characterize the waste to ICDF Complex personnel for review.

- $\quad$ The waste generator prepares a waste profile using instructions found in the ICDF Complex WAC (DOE/ID-10881 [DOE-ID 2006a]) and the ICDF Complex Waste Tracking Plan (PLN-914).

- ICDF Complex personnel review the waste profile as described in PLN-914. If there is a conflict between the waste profile and the waste generator's hazardous waste determination, ICDF personnel will work with the generator to resolve the discrepancy, which may include additional sampling.

- $\quad$ For each container sent to the ICDF, an IWTS container profile is completed and a shipment date/time is assigned.

- ICDF personnel perform waste visual verification in accordance with this document. Verification may occur either at the dig site or at the ICDF Complex.

- Upon receipt of the waste shipment from the waste generator, a receipt inspection of the waste will be performed as an additional assurance.

- After receipt inspection is completed, the waste will be placed in the landfill according to the ICDF waste placement plan.

\subsection{ICDF Waste Profile Review Process}

As the first phase of waste acceptance, the generator-supplied waste and container profiles and supporting data will undergo a thorough review by ICDF Complex personnel. The review will be conducted to first determine if the characterization performed by the waste generator was adequate, followed by a review of the data to determine if the waste meets the applicable WAC concentration guidelines. 


\subsubsection{Generator Waste Profile and Data Package Review}

ICDF Complex personnel will review the characterization data packages and waste profiles developed by the waste generators to ensure the data was obtained using appropriate sampling and analytical methods. ICDF personnel will consider the following factors when performing this assessment: the generator's SAP, the waste form, volume of waste, and the complexity of the waste stream (e.g., homogeneity, radiological characteristics, and significant concentrations of key parameters).

ICDF personnel will use the guidance provided in this document as a basis for establishing whether a waste generator has satisfied the burden for developing a data package consistent with DQOs. Any discrepancies or deficiencies identified during this evaluation will be brought to the generator's attention for resolution. ICDF personnel may require additional sampling and analysis to be conducted or additional information from generators to adequately resolve any deficiencies noted.

\subsubsection{Waste Acceptance Criteria Review Process}

Once the waste generator's data have been deemed acceptable, a review will be conducted of the key regulated parameters present in each waste stream to ensure the waste is within established WAC limits for the ICDF. The objective of the waste acceptance criteria review process is to ensure that key parameters in the waste do not exceed the operational and regulatory limits for ICDF. Key parameters have been identified as those parameters that impact ICDF operations or limit acceptance of waste in the landfill, as defined by the ICDF Complex WAC (DOE/ID-10881 [DOE-ID 2006a]) and/or operational limits. Key parameter groupings include:

- $\quad>5 \%$ Void space (applicable to debris waste only)

- $\quad$ Free liquids

- Transuranic waste constituents $>10 \mathrm{nCi} / \mathrm{g}$

- Landfill contaminants of concern (see Table B-1)

- Land disposal restrictions

- Idaho Administrative Procedures Act (IDAPA) operational limits

- National Emission Standards for Hazardous Air Pollutants (NESHAP) operational limits

- Generator CERCLA documentation (i.e., engineering evaluation/cost analysis [EE/CA]).

Table 5-1 summarizes the soil waste acceptance requirements for the IDAPA and NESHAP key parameter groupings. The review process for these parameters is described in Section 5.1.2.1. Assessment for void space in individual waste packages is a verification criterion and is addressed in Section 5.2.2.1, since void space is only applicable to debris waste. Waste acceptance criteria limits for LDR, landfill COC, and TRU key parameter groupings are addressed in Section 5.1.2.2.

5.1.2.1 IDAPA and NESHAPS Acceptance Reviews. For those key parameters that are driven by mass-based operational limits (i.e., IDAPA and NESHAP shown in Table 5-1), waste acceptance and placement control will be achieved through administrative controls. The ICDF WAC lead will perform calculations in advance of waste receipt to verify the waste is within the applicable WAC limits. For NESHAP key parameters, the NESHAP limits are greater than the landfill WAC limits; therefore, by ensuring that the parameters are within the landfill WAC, as defined in the ICDF Complex WAC (DOE/ID-10881 [DOE-ID 2006a]), the administrative controls will ensure that the parameters are below the applicable NESHAP limits. 
Table 5-1. Acceptance requirements for IDAPA and NESHAP key parameters in soil waste.

\begin{tabular}{|c|c|c|c|c|c|c|}
\hline \multirow[b]{2}{*}{ Key Parameter } & \multirow{2}{*}{$\begin{array}{l}\text { Applicable } \\
\text { Limit }\end{array}$} & \multirow{2}{*}{$\begin{array}{c}\text { Type of Limit } \\
\text { (Document Reference) }\end{array}$} & \multicolumn{2}{|c|}{ Waste Profile Compared to the Applicable Limit } & \multicolumn{2}{|c|}{ Applicable Methods } \\
\hline & & & $<80 \%$ & $\geq 80 \%$ & $<80 \%$ & $\geq 80 \%$ \\
\hline \multicolumn{7}{|l|}{ IDAPA $^{a}$} \\
\hline Hexachlorobenzene & $4.76 \mathrm{~kg} / \mathrm{day}$ & \multirow{3}{*}{$\begin{array}{l}\text { Mass-based operational } \\
\text { (ICDF Complex WAC } \\
\text { DOE/ID-10881 } \\
\text { [DOE-ID 2006a]) }\end{array}$} & \multirow{3}{*}{$\begin{array}{l}\text { Administrative } \\
\text { controls }^{\mathrm{b}}\end{array}$} & \multirow{3}{*}{$\begin{array}{l}\text { Administrative controls }{ }^{\mathrm{b}} \text { and } \\
\text { delay waste placement }^{\mathrm{c}}\end{array}$} & \multirow{3}{*}{\multicolumn{2}{|c|}{ Technical procedure }} \\
\hline Ethyl cyanide (as CN) & $2,390 \mathrm{~kg} / \mathrm{day}$ & & & & & \\
\hline Mercury & $74 \mathrm{~kg} /$ day & & & & & \\
\hline \multicolumn{7}{|l|}{ NESHAP $^{\mathrm{d}}$} \\
\hline Cs-137 & $113,360 \mathrm{Ci} / \mathrm{yr}$ & \multirow{2}{*}{$\begin{array}{l}\text { Mass-based operational (ICDF } \\
\text { RD/CWP DOE/ID-10848 } \\
\text { [DOE-ID 2002], Appendix O) }\end{array}$} & \multirow{2}{*}{$\begin{array}{l}\text { Administrative } \\
\text { controls }^{\mathrm{e}}\end{array}$} & \multirow{2}{*}{$\begin{array}{l}\text { Administrative controls } \mathrm{e}^{\mathrm{e}} \text { and } \\
\text { delay waste placement }\end{array}$} & \multirow{2}{*}{\multicolumn{2}{|c|}{ Technical procedure }} \\
\hline $\mathrm{I}-129$ & $5.9 \mathrm{Ci} / \mathrm{yr}$ & & & & & \\
\hline \multicolumn{7}{|c|}{$\begin{array}{l}\text { a. Key IDAPA parameters are defined as those parameters that have WAC guideline concentrations greater than the guideline concentration based on the mass-based operational } \\
\text { limits. }\end{array}$} \\
\hline \multicolumn{7}{|c|}{$\begin{array}{l}\text { b. Since IDAPA concerns are driven by operational limits that are mass-based, and not concentration-based, verification is performed by administrative controls. These } \\
\text { administrative controls are achieved through IWTS scheduling checks performed in advance of waste receipt and in transaction checks performed at the time of waste receipt. } \\
\text { These IWTS checks ensure that the total mass received for the day from all generators is below the limit. }\end{array}$} \\
\hline \multicolumn{7}{|c|}{$\begin{array}{l}\text { c. For each of the IDAPA key parameters, if the total mass expected for the day is } \geq 80 \% \text { of the daily limit, then some of the waste will be staged to delay placement and ensure } \\
\text { that the total daily load is below } 80 \% \text { of the daily limit. }\end{array}$} \\
\hline \multicolumn{7}{|c|}{$\begin{array}{l}\text { d. Key NESHAP parameters are defined as those parameters that were major contributors to the estimated yearly dose to the Site boundary as summarized in Table } 8 \text { of } \\
\text { Appendix O of the ICDF Remedial Design/Construction Work Plan (DOE/ID-10848 [DOE-ID 2002]). Iodine- } 129 \text { was identified as the major contributor to the landfill operation } \\
\text { dose at } 96.6 \% \text {. Cesium-137 contributed less than } 2 \% \text { to the landfill operation dose. All other sources contributed less than } 1 \% \text {. The limits shown are obtained from Table } 3 \text { of the } \\
\text { same appendix, from the maximum yearly input and adjusted to maintain a maximum off-Site exposure of } 1 \text { mrem/year. }\end{array}$} \\
\hline \multicolumn{7}{|c|}{ e. Since NESHAP concerns are driven by operational limits that are mass-based, and not concentration-based, verification is performed by administrative controls. } \\
\hline \multicolumn{7}{|c|}{ f. If administrative controls indicate that operational limits will be exceeded, the waste will be staged to delay placement and ensure that the operation limits are met. } \\
\hline \multicolumn{7}{|c|}{ ICDF = Idaho CERCLA Disposal Facility } \\
\hline \multicolumn{7}{|c|}{ ICDF RD/CWP = INEEL CERCLA Disposal Facility Remedial Design/Construction Work Plan (DOE/ID-10848 [DOE-ID 2002]). } \\
\hline \multicolumn{7}{|c|}{ IDAPA = Idaho Administrative Procedures Act } \\
\hline \multicolumn{7}{|c|}{ IWTS = Integrated Waste Tracking System } \\
\hline \multicolumn{7}{|c|}{ NESHAP = National Emission Standards for Hazardous Air Pollutants } \\
\hline $\mathrm{WAC}=$ waste acceptance cri & & & & & & \\
\hline
\end{tabular}


Waste with key parameters that have reached $\geq 80 \%$ of the mass-based operational limits (either for a given day or year) will be staged to delay waste placement to ensure that the mass-based limit is not exceeded. For example, if the total mass expected for the day is $\geq 80 \%$ of the daily limit for any of the individual IDAPA key parameters, then some of the waste will be staged to delay placement and ensure that the total daily load is below $80 \%$ of the daily limit.

\subsubsection{Land Disposal Restriction, Landfill Contaminant of Concern, and Transuranic Key Parameter Acceptance Review. The WAC limits for LDR, landfill COC, and TRU key} parameters are discussed in the applicable section (e.g., landfill, evaporation pond) of the ICDF Complex WAC (DOE/ID-10881[DOE-ID 2006a]). The WAC limits for the ICDF were developed through extensive modeling to determine the maximum mass of each constituent that can be safely and compliantly disposed of in the landfill. These maximum mass limits were then used to calculate the average maximum allowable concentration for each constituent by dividing the allowable mass by the total landfill capacity of $510,000 \mathrm{yd}^{3}$.

For bulk soil, the WAC concentration guidelines serve as a conservative initial WAC limit to be evaluated. In the event that a material profile concentration exceeds the published WAC concentration guideline for any given constituent, ICDF personnel will calculate the mass of that constituent using the generator-supplied concentration data. ICDF personnel will compare the calculated mass limit against the landfill running/current total mass documented in the ICDF waste inventory databases for the constituent(s) in question to determine whether acceptance of the waste will result in the exceedance of a WAC mass limit. If the constituent mass is less than the published WAC mass limit, the waste stream is approved.

To calculate the landfill inventory constituent-specific activities/masses, ICDF personnel use the following process:

- $\quad$ For constituents with positive analytical detections at or below the detection limits, a value of one half of the analytical detection limit will be used to determine the maximum potential mass for that constituent. The mean value for all samples collected for a given sampling event or waste stream will be used to determine the activity/mass loading of the landfill, as it is most representative of the waste stream.

- $\quad$ The activities/masses are added to the current/running landfill activity/mass (e.g., kilograms and curies) and compared to the approved/published WAC activity/mass. If the sum is less than $50 \%$ of the approved/published WAC activity/mass (e.g., kilograms and curies), the waste stream will be approved and the waste accepted. In the event the sum exceeds $50 \%$ of the approved/published WAC activity/mass limits, waste stream approval will be withheld until conditions/circumstances allow acceptance of the waste stream that precludes all potential for an activity/mass limit exceedance (i.e., the landfill is almost full and constituent activity/mass are available, higher activity/mass limits are negotiated with the agencies, or projection for all future waste streams does not result in exceeding $90 \%$ of the mass/curie limits).

- If a constituent proven to be a risk to human health and the environment is present in a waste stream at greater than $75 \%$ of the corresponding landfill mass limit, additional sampling may be required in accordance with Appendix B. Table B-1 contains a list of those constituents subject to this additional sampling should their mass in a waste stream exceed $75 \%$ of the available landfill mass limit for that constituent. Constituents not identified in Appendix A, Table A-1, are not subject to the additional sampling in Appendix B unless they exceed $90 \%$ of the applicable mass limit. WAC-regulated constituents used as contamination fixatives, or as part of the waste 
packaging materials (iron, etc.), are not considered waste; the mass of such constituents should not be included on the waste profile.

Organic landfill COCs (2-nitroaniline, 3-nitroaniline, 4-nitroaniline) have only been identified at one site that will be disposing of soil waste to the landfill. This site has a volume of less than $2 \%$ of the total $510,000-\mathrm{yd}^{3}$ volume of the landfill. Since the limits for the landfill COC key parameters are based on mass limits assuming a maximum concentration over the entire landfill, these parameters cannot limit operations of the landfill. Acceptance requirements are also not identified for I-129, which is one of the radiological landfill COCs. Iodine-129 is highly mobile and therefore is a major concern for groundwater, primarily due to the contributions from release sites at INTEC.

The following equation shows the correct way to determine mass for I-129:

$$
\bar{\chi} \times \mathrm{V}+\mathrm{Z}_{1-\alpha} \times \sqrt{\frac{\mathrm{s}^{2} \times \mathrm{V}^{2}}{\mathrm{n}}},
$$

where

$$
\begin{aligned}
& \bar{\chi}=\text { mean of the }{ }^{129} \mathrm{I}(\mathrm{Ci} / \mathrm{g}) \text { sample results, } \\
& \mathrm{V}=\text { mass of }{ }^{129} \mathrm{I} \text { bearing waste }(\mathrm{g}), \\
& \mathrm{Z}_{1-\alpha}=1-\alpha \text { percentile of the standard normal distribution, } \\
& \mathrm{s}^{2}=\text { variance of the }{ }^{129} \mathrm{I} \text { sample results, and } \\
& \mathrm{n}=\quad \text { number of samples from the volume of }{ }^{129} \mathrm{I} \text { bearing waste. }
\end{aligned}
$$

For the release sites suspected of having detectable I-129 concentrations (examples of such sites include but are not limited to CPP-36/91, -37B, $-67,-92,-97,-98$, and -99), the waste generator will be required to perform additional characterization of the I-129 curie content before completion of the waste profile. The characterization of I-129 for these sites will be addressed either in the SAP prepared as part of the Remedial Action Work Plan for the site or as a modification of the ICDF Remedial Action Work Plan (DOE/ID-10984 [DOE-ID 2003a]). As part of this effort, determination of I-129 acceptability may be achieved through the characterization. The I-129 mass will be determined from the waste volume times the $95 \%$ upper confidence limit (UCL) of the mean activity. The ICDF landfill WAC limits for I-129 are $2.4 \mathrm{Ci}$, as defined in the ICDF Complex WAC document (DOE/ID-10881 [DOE-ID 2006a]). Based on this limit and the characterization results, the concentration guidelines may be adjusted to account for the expected volume of I-129 contaminated soil being placed in the ICDF landfill. Additionally, the IWTS database performs a review against the Authorization Safety Agreement and the Nuclear Category 3 limits as part of the waste profile acceptance process.

\subsection{Verification}

As the second phase of waste acceptance, ICDF personnel will perform waste verification. The purpose of the waste verification activities for the ICDF Complex is to ensure that each waste shipment proposed for receipt at the Complex matches the information on the approved waste and container profile and does not exceed the mass limits. The waste generator is responsible for conducting detailed sampling and analysis of each waste stream and recording the data on the waste and container profile as described in Section 4 of this document. ICDF Complex personnel conduct detailed reviews of the information contained in the waste profile to ensure that the proposed waste stream meets the applicable WAC. As part of this review, the ICDF personnel also evaluate the adequacy of the generator's characterization 
approach and data. Any discrepancies are resolved before acceptance of the waste at ICDF. Since all of the quantitative characterization activities will already have been completed, the waste verification conducted for each waste shipment will ensure that the observable characteristics match the waste profile; this could include fingerprint receipt sampling.

The approach for conducting qualitative fingerprint sampling for verification is suitable for the waste being shipped to the ICDF. Examples of typical qualitative fingerprint sampling techniques that may be used by ICDF personnel to conduct waste verification may include but are not limited to visual examination (e.g., for such indicators as color, presence of prohibited items, and multiphases), moisture testing, $\mathrm{pH}$, flash point, etc. The use of these techniques will assure ICDF personnel that the waste received matches the characteristics defined on the waste profile. All waste to be managed in the facility will be generated at the INL. The ICDF therefore does not accept off-Site waste that would require a more rigorous verification program. Since the INL is the waste generator and the receiving facility, there is marginal value added to perform additional sampling and analysis as part of waste verification as long as the initial characterization was conducted to meet the requisite confidence and quality assurance/quality check requirements addressed in this guidance.

Verification requirements for waste destined to the ICDF Complex depend on the media being disposed of to the landfill. The waste handling at the ICDF landfill shall maintain worker exposure as low as reasonably achievable (ALARA) as specified in the ICDF Complex WAC (DOE/ID-10881

[DOE-ID 2006a]), in accordance with DOE Order 5400.5, "Radiation Protection of the Public and the Environment." Therefore, risks to workers have been limited. Allowable WAC concentrations or operational limits are reflected in Table 5-1 and the ICDF Complex WAC document (DOE/ID-10881 [DOE-ID 2006a]). Should ALARA concerns arise with any of the waste being verified, verification of that waste will cease and the proper path forward will be determined in accordance with applicable DOE requirements and INL procedures on a waste-profile-specific basis. The following subsections describe the verification process for the various media, assuming no ALARA concerns are identified.

\subsubsection{Verification Requirements for Waste Area Group 3 Water and ICDF-Generated Waste}

Water resulting from WAG 3 activities will be direct disposed of to the ICDF evaporation pond and not to the landfill. (Refer to the section titled "Waste Acceptance Criteria for the ICDF Evaporation Pond" [i.e., Section 6] of the ICDF Complex WAC [DOE/ID-10881 (DOE-ID 2006a)]). Contaminant concentrations reported from the waste characterization activities of these water wastes are representative of the concentrations in the water itself. The results of the waste characterization will be required before completion of the associated waste profile. The ICDF waste specialist will review analytical data from the waste characterization process against the associated waste profile prior to approval of the waste profile. Additional verification of these wastes is not required.

Waste generated as a result of ICDF operations will be sampled and analyzed according to specifications in existing ICDF documents. Additional verification of these wastes is not required. Sampling and analysis requirements for waste generated from ICDF groundwater monitoring activities are addressed in the ICDF Groundwater Monitoring Plan (DOE/ID-10955 [DOE-ID 2004]), while sampling and analysis requirements for other ICDF sample streams are covered in the ICDF Complex Operational and Monitoring Sampling and Analysis Plan (DOE/ID-11005 [DOE-ID 2003b]) and the ICDF Complex Operations Waste Management Plan (DOE/ID-10886 [DOE-ID 2003c]). 


\subsubsection{Verification Requirements for Debris Waste}

Debris waste will be accepted at the landfill if the waste meets the specific landfill WAC (DOE/ID-10881 [DOE-ID 2006a]). It is expected that some waste generators will have already containerized their debris waste prior to initiation of ICDF Complex operations. Some debris waste will require treatment before disposal and thus will not be direct disposed of to the landfill. Treatment requirements for debris waste are addressed in the ICDF Complex Operations and Maintenance Plan (DOE/ID-11000 [DOE-ID 2006b]). Since the debris treatment process is a performance-based standard, verification requirements for these debris wastes are not addressed in this plan. The following sections describe the verification process for the debris waste that does not require treatment before disposal at the landfill.

\subsubsection{Verification Requirements for Debris Waste Not Containing Transuranic} Parameters. Debris waste that does not require treatment prior to disposal at the landfill will undergo verification. For debris waste not containing TRU parameters, the two steps of this verification are (1) $100 \%$ visual inspection, either as the waste is being containerized or by opening the container, and (2) verification of the associated documentation. (Refer to Section 5.2.2.2 for the verification requirements for debris waste that contains TRU constituents.) Visual inspection will ascertain that the waste contains material that meets the definition of debris as defined in 40 CFR 268.2(g) "DebrisGeneral-Land Disposal Restrictions," and that each waste container identified on the profile as debris includes greater than $50 \%$ debris. Visual inspection will ensure that the specific type of debris waste being sent for disposal is as specified in the waste profile. For containerized waste that remains in the intact container following disposal, verification will ensure that the waste fills at least $95 \%$ of the internal volume of the container, thus limiting the void space to less than $5 \%$. Note that when the void space exceeds $5 \%$, the interior of the container will be grouted to fill the void space. Verification of the documentation and/or calculations used to establish the waste profile will be performed before approval of the waste profile to ensure key parameters are adequately addressed and that the calculations are accurate. Refer to Section 5.1 for the key parameter groupings.

\subsubsection{Verification Requirements for Debris Waste Containing Transuranic}

Parameters. Key TRU parameters are those radiological parameters identified in the landfill section (Section 5) of the ICDF Complex WAC (DOE/ID-10881 [DOE-ID 2006a]). These include Np-237, $\mathrm{Pu}-238, \mathrm{Pu}-239, \mathrm{Pu}-242, \mathrm{Pu}-244, \mathrm{Am}-241, \mathrm{Am}-243, \mathrm{Cm}-243, \mathrm{Cm}-245, \mathrm{Cm}-246, \mathrm{Cm}-248, \mathrm{Cm}-250$, Bk-247, Cf-249, and Cf-251. The quantity of TRU radionuclides present in the debris waste will be specified by the waste generator on the waste profile. Verification of the reported TRU content will be performed by an independent ICDF review of the characterization documentation prepared by the waste generator. The characterization documentation prepared by the waste generator will contain the activities, or concentrations, of TRU parameters listed on the waste profile. The independent ICDF review will be performed by a subject matter expert and, at a minimum, will verify the documentation contents for the following elements:

- $\quad$ Detailed list of known waste parameters including but not limited to the following: waste composition; physical properties of final waste form (density, weight, dimensions, and void space in package); waste package material; radiological source term; radiological exposure rates for waste and/or waste package; and radioanalytical data.

- Detailed list of reasonable assumptions including but not limited to the following: waste composition, density, void space, estimated radiological exposure rates, and estimated radiological source term. 
- Description of calculation basis and methodology (i.e., hand calculations should include references for equations used; computer modeling should reference computer code user's manual). The calculations/modeling should be explicit, and input parameters should match the known waste parameters and assumptions.

- $\quad$ Detailed list of the TRU radionuclides and the associated concentrations in the final waste form.

- $\quad$ Debris waste containing TRU parameters will not undergo visual inspection.

5.2.2.3 Assessment of Debris Verification Results. Verification of debris waste will be performed under the direction of the ICDF waste specialist (or designee). Debris waste that fails the visual inspection or the verification of the associated documentation will not be allowed in the landfill as is and corrective action will be initiated. At a minimum, the corrective action could include a revision to the waste profile by the waste generator, addition of material to meet void space requirements, or rejection of the waste.

\subsubsection{Verification Requirements for Soil Waste}

All waste soils should have been thoroughly characterized by the waste generator. Verification of soil for acceptance into the ICDF will consist of qualitative field methods including visual examination, procedural and administrative controls. In the event that these quantitative methods do not provide sufficient assurance that the waste is consistent with the Material Profile, ICDF personnel may employ field sampling techniques as part of the waste verification process.

Visual inspections are required to ensure that the physical characteristics of the soil waste do not differ from the source characterization information, as specified on the waste profile, or, in the case of free liquids, to visually look for as well as implement procedural controls to ascertain the presence of free liquids before shipment to the ICDF Complex. Visual inspections seek qualitative indicating parameters such as soil color, presence of uncharacterized debris, other suspect materials, and excessive free liquids. Visual inspection will be performed on a daily basis prior to disposal, either at the excavation site or at the ICDF on containers prior to disposal in the landfill cell.

If soils appear wet or are being handled during inclement weather, then the generator shall follow the instructions in the applicable Interface Agreement regarding avoidance of free liquids and/or take steps to eliminate the presence of free liquids. A $100 \%$ visual inspection is necessary to ensure no free liquid is connected with the soil waste. Free liquid is defined as water puddling or collecting on the soil in the container/truck. Some soil moisture is expected from either natural processes or the addition of water to minimize dust or control contamination. Inspections will be conducted at the excavation site or from waste containers by the waste generator representative at the generator's facility. Visual inspection of soil as it is loaded is preferred, as it allows visual observation of the soil condition.

Verification of soil waste with key parameters that are mass-based (i.e., IDAPA and NESHAP parameters) will be performed through administrative controls, which will be achieved through the use of data from a waste-tracking database (e.g., IWTS).

Organic landfill COCs (2-nitroaniline, 3-nitroaniline, 4-nitroaniline) have been identified at only one site that will be disposing of soil waste to the landfill. This site has a volume of less than $2 \%$ of the total $510,000-\mathrm{yd}^{3}$ volume of the landfill. Since the limits for the landfill COC key parameters are based on mass limits assuming a maximum concentration over the entire landfill, these parameters cannot limit operations of the landfill. Verification requirements also are not identified for I-129, which is one of the radiological landfill COCs. Iodine-129 is highly mobile and therefore is a major concern for groundwater, 
primarily due to the contributions from release sites at INTEC. For the release sites suspected of having detectable I-129 concentrations (e.g., CPP-36/91, -37B, -67, -92, -97, -98, and -99), the generator will be required to perform additional characterization of the I-129 curie content prior to completion of the Material Profile. Characterization and verification of I-129 for these sites will either be addressed in the SAP prepared as part of the Remedial Design/Remedial Action (RD/RA) Work Plan for the site or as a modification of the ICDF Complex RAWP (DOE/ID-10984 [DOE-ID 2003a]). As part of this effort, verification of I-129 may be achieved through the characterization. The ICDF landfill WAC limits for I-129 are $2.4 \mathrm{Ci}$. Based on this limit and the characterization results, the concentration guidelines may be adjusted to account for the expected volume of I-129 contaminated soil being placed in the ICDF landfill.

\subsubsection{Verification Requirements for Liquid Waste Managed at the ICDF Evaporation Ponds}

ICDF Complex personnel perform detailed reviews of waste profile and supporting documentation for liquid waste proposed for discharge to the ICDF evaporation ponds. No additional waste verification is conducted for the liquid waste. If during the review, ICDF Complex personnel identify a liquid waste stream that may have the potential to have multiphases, or a high solids content $(>1 \%)$, additional characterization information by the generating organization will be required to determine whether the waste meets the applicable WAC for the ponds. Insufficient data will result in rejection of the waste during the profile review process; therefore, no physical verification sampling will be necessary prior to acceptance at the ICDF.

\subsubsection{Assessment of Verification Results}

If the results from the required verification (e.g., visual inspection, procedural controls, and administrative controls) for key parameters indicate that the proposed waste shipment matches the description provided on the applicable waste and container profile for the shipment, the waste can be accepted for management at the ICDF Complex. For verification involving visual inspections, procedural controls, administrative controls, or field-measured sample results, verification can be obtained in a matter of minutes or hours.

If the results from the visual inspections, procedural controls, or administrative controls indicate that the waste is not as expected on the waste profile, then the waste will not be accepted at the landfill as is and corrective action will be initiated. At a minimum, the corrective action would include a review of the source characterization information and a possible revision to the waste profile by the waste generator. For those waste streams with key parameters determined from mass-based operational limits - if the administrative controls indicate that key parameters are $\geq 80 \%$ of the operation limit - then the action taken could be as simple as delaying placement of the waste until a time that the key parameter is below $80 \%$ of the operational limit. 


\section{REFERENCES}

10 CFR 61.55, 2005, "Waste Classification," Code of Federal Regulations, Office of the Federal Register, November 2005.

40 CFR 260.10, 2006, "Definitions-Hazardous Waste Management System: General," Code of Federal Regulations, Office of the Federal Register, July 2006.

40 CFR 261, 1999, "Identification and Listing of Hazardous Waste," Code of Federal Regulations, Office of the Federal Register, July 1999.

40 CFR 268, 1999, "Land Disposal Restrictions," Code of Federal Regulations, Office of the Federal Register, July 1999.

40 CFR 268.2(g), 1999, "Debris-General-Land Disposal Restrictions," Code of Federal Regulations, Office of the Federal Register, July 1999.

40 CFR 268.45, 2006, “Treatment Standards for Hazardous Debris," Code of Federal Regulations, Office of the Federal Register, July 2006.

40 CFR 268.49, 1999, “Alternative LDR Treatment Standards for Contaminated Soil," Code of Federal Regulations, Office of the Federal Register, July 1999.

40 CFR 761, 2006, "Polychlorinated Biphenyls (PCBs) Manufacturing, Processing, Distribution in Commerce, and Use Prohibitions," Code of Federal Regulations, Office of the Federal Register, June 2006.

15 USC $\S 2601$ et seq., 1976, “Toxic Substance Control Act (TSCA) of 1976," United States Code, October 11, 1976.

42 USC $§ 6901$ et seq., 1976, Subtitle C, "Hazardous Waste Management," — "Resource Conservation and Recovery Act of 1976," United States Code (as amended), October 21, 1976.

42 USC $§ 9601$ et seq., 1980, “Comprehensive Environmental Response, Compensation and Liability Act of 1980 (CERCLA/Superfund)," United States Code, December 11, 1980.

DOE O 435.1, Change 1, 2001, "Radioactive Waste Management," U.S. Department of Energy, August 2001.

DOE O 5400.5, Change 2, 1993, "Radiation Protection of the Public and the Environment," U.S. Department of Energy, January 1993.

DOE-ID, 1999, Final Record of Decision, Idaho Nuclear Technology and Engineering Center, Operable Unit 3-13, DOE/ID-10660, Rev. 0, Department of Energy Idaho Operations Office, U.S. Environmental Protection Agency Region 10, and State of Idaho Department of Health and Welfare, October 1999.

DOE-ID, 2002, INEEL CERCLA Disposal Facility Remedial Design/Construction Work Plan, DOE/ID-10848, Rev. 1, U.S. Department of Energy Idaho Operations Office, May 2002.

DOE-ID, 2003a, INEEL CERCLA Disposal Facility Complex Remedial Action Work Plan, DOE/ID-10984, Rev. 0, U.S. Department of Energy Idaho Operations Office, February 2003. 
DOE-ID, 2003b, ICDF Complex Operational and Monitoring Sampling and Analysis Plan, DOE/ID-11005, Rev. 0, U.S. Department of Energy Idaho Operations Office, February 2003.

DOE-ID, 2003c, ICDF Complex Operations Waste Management Plan, DOE/ID-10886, Rev. 0, U.S. Department of Energy Idaho Operations Office, February 2003.

DOE-ID, 2004, ICDF Groundwater Monitoring Plan, DOE/ID-10955, Rev. 3, U.S. Department of Energy Idaho Operations Office, March 2004.

DOE-ID, 2006a, ICDF Complex Waste Acceptance Criteria, DOE/ID-10881, Rev. 3, U.S. Department of Energy Idaho Operations Office, October 2006.

DOE-ID, 2006b, ICDF Complex Operations and Maintenance Plan, DOE/ID-11000, Rev. 2, U.S. Department of Energy Idaho Operations Office, February 2006.

DOE-ID, 2006c, Quality Assurance Project Plan for Waste Area Groups 1, 2, 3, 4, 5, 6, 7, 10, and Removal Actions, DOE/ID-10587, Rev. 9, U.S. Department of Energy Idaho Operations Office, July 2006.

EPA, 1999, "Test Methods for Evaluating Solid Waste, Physical/Chemical Methods," Third Edition, SW-846, U.S. Environmental Protection Agency, 1999.

EPA, 2002, RCRA Waste Sampling Draft Technical Guidance, Planning, Implementation, and Assessment, U.S. Environmental Protection Agency, Office of Solid Waste and Emergency Response EPA 530-D-02-002, August 2002.

HWMA, 1983, “Hazardous Waste Management Act of 1983," Idaho Code Sections 39-4401 et seq., 1983.

NRC, 1995, Issuance of Final Branch Technical Position on Concentration Averaging and Encapsulation, Revision in Part to Waste Classification Technical Position, U.S. Nuclear Regulatory Commission, Washington D.C.

PLN-914, 2006, "Waste Tracking Plan for the Idaho CERCLA Disposal Facility Complex," Rev. 1, Department of Energy Idaho Operations Office, March 2006. 


\section{Appendix A}

\section{Waste Sampling, Analysis, and Data Quality Management Guidance}




$$
\text { A-2 }
$$




\section{Appendix A}

\section{Waste Sampling, Analysis, and Data Quality Management Guidance}

\section{Introduction}

The information contained in this appendix provides characterization guidance to be followed by waste generators profiling Comprehensive Environmental Response, Compensation, and Liability Act (CERCLA) response action waste for management at the Idaho CERCLA Disposal Facility (ICDF) Complex. It is the generator's responsibility to properly characterize each waste stream proposed for shipment to the ICDF Complex in a manner that meets data quality objectives (DQOs) to demonstrate compliance with the applicable waste acceptance criteria (WAC). ICDF Complex personnel will perform detailed reviews of the characterization data packages and waste profiles developed by the waste generators to determine whether the data are sufficient and accurate to demonstrate WAC compliance. If ICDF Complex personnel determine that the generator-supplied information does not meet quality standards, the waste stream may not be accepted and the generator will be required to perform additional sampling and analysis to obtain the requisite level of data. This appendix provides waste generators with the necessary guidance to develop complete data packages for waste streams being shipped to the ICDF. ICDF Complex personnel will review the data packages against the information contained in this appendix for adequacy.

It is anticipated that many of the potential waste streams proposed for shipment to the ICDF Complex have already had some degree of waste characterization performed on them, including characterization conducted as part of the remedial investigation/feasibility study (RI/FS) scoping process and other CERLCA planning activities. This initial data will not be adequate in many cases to allow the ICDF Complex personnel to accept a given waste stream into the Complex for management. However, these data are useful for providing an initial basis to establish the final sampling and analysis schemes. Furthermore, it is anticipated that these data can be used if supplemented by additional sampling and analytical activities to obtain the necessary level of data quality to ensure compliance with the applicable WAC. 


\section{A-1. SAMPLE AND MEASUREMENT METHODS}

\section{A-1.1 Sample Collection Methods}

A scoop, hand corer, auger, or other typical soil sample collection tool generally will be used to collect soil samples. Prior to collection of any samples, the sample tool will be decontaminated to prevent cross-contamination of samples.

For each required characterization sample, the sample location within the waste container or from the population unit within the unexcavated site will be chosen to be representative of the waste, and the sample will be collected from this location. All samples will be collected in their appropriate containers based on the contaminant and the associated analytical method required for the analytical data. As discussed in Section A-1.2, on-Site analysis and/or off-Site analytical laboratories will be used to obtain the analytical results, depending on the contaminant, required detection level, and analytical technique. For samples associated with on-Site analysis, no sample container is required for those analyses performed in situ. Samples to be analyzed on-Site, but not in situ, will be collected in an appropriate container. All samples requiring off-Site laboratory analysis must be collected in pre-cleaned sample containers and will follow the container requirements identified in the Quality Assurance Project Plan for Waste Area Groups 1, 2, 3, 4, 5, 6, 7, 10 and Removal Actions (QAPjP) (DOE/ID-10587

[DOE-ID 2006a]). If a sample container is required for a volatile organic compound (VOC), then it will be the first sample collected so it can be obtained before any additional mixing of the soil. The sample also will be taken such that the sample container is completely filled with minimal headspace to control any loss of target analytes due to aeration.

\section{A-1.2 Measurement Methods}

The following sections present a discussion of the analytical methods that are acceptable for use to obtain the results required for waste characterization. Additional analytical methods, not listed in the following sections, may be used to obtain the waste characterization results, provided there is a standard method with acceptable detection limits to demonstrate compliance with the applicable WAC for expected constituents. Use of all on-Site analytical methods will follow the manufacturer's operating procedures and any procedures developed to test waste at the required level of detection. Off-Site analytical laboratories will be approved by the INL in accordance with applicable laboratory procurement procedures. Table A-1 provides a summary of the methods discussed in the following sections and method detection limits (MDLs) for each (when available or determined). The methods listed in the table as "Field Methods" are the methods that are most likely to be available at the INL for on-Site analysis. The methods listed as "Laboratory Methods" are typically performed in off-Site laboratories.

\section{A-1.2.1 Methods Applicable for Characterization of Key Land Disposal Restriction Parameters}

The following sections describe the analytical methods that will be used for the various parameter classifications necessary to characterize waste for acceptance at the ICDF Complex.

A-1.2.1.1 Volatile Organics. Applicable VOCs must be measured in the soil destined for disposal at the landfill if a VOC that is subject to the alternative land disposal requirement (LDR) treatment standards for contaminated soils found in 40 CFR 268.49 is present in the soil. 
Table A-1. Potential methods for performing the required measurements of constituent concentrations in waste characterization samples.

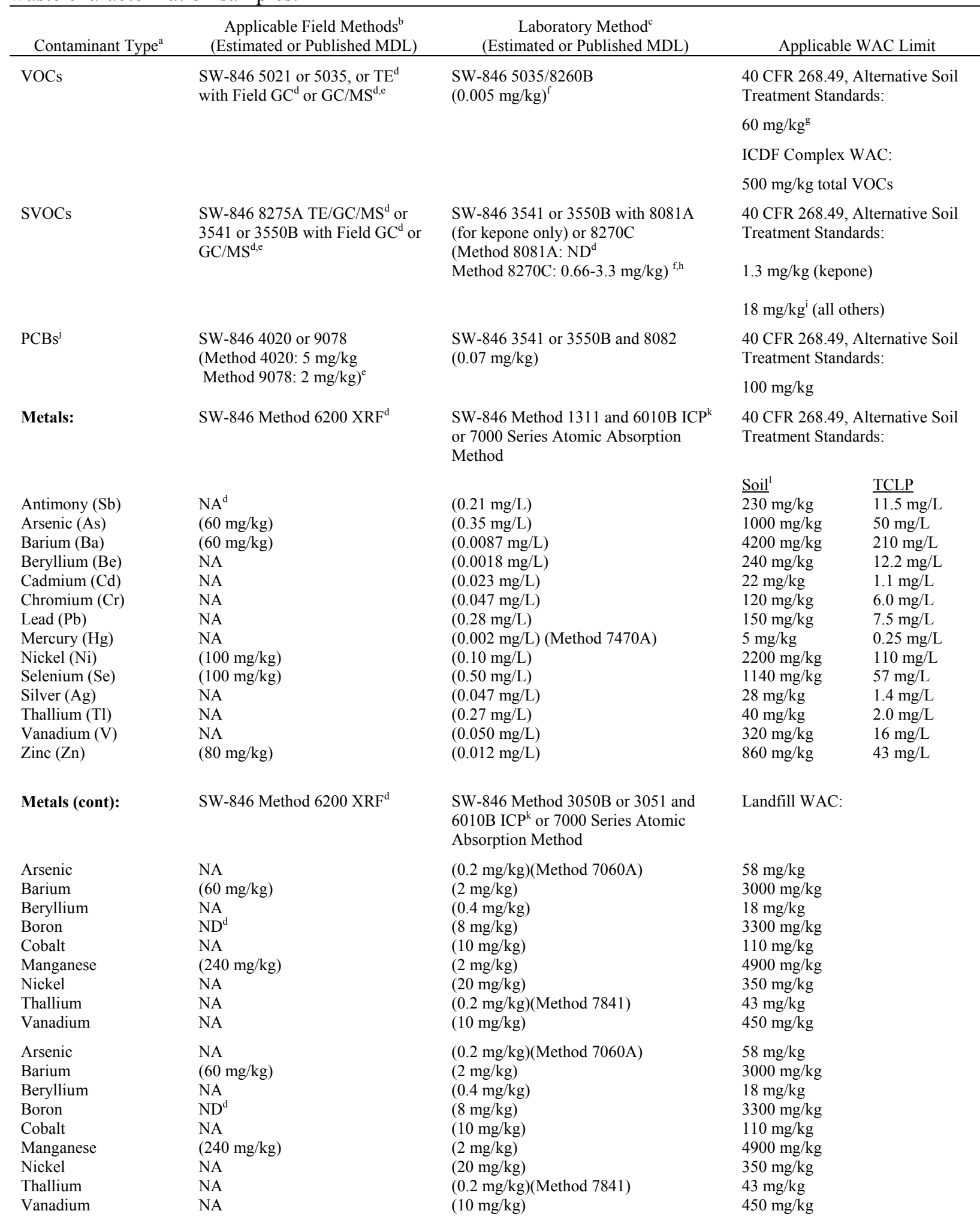


Table A-1. (continued).

\begin{tabular}{|c|c|c|c|}
\hline Contaminant Type ${ }^{\mathrm{a}}$ & $\begin{array}{c}\text { Applicable Field Methods }{ }^{\mathrm{b}} \\
\text { (Estimated or Published MDL) }\end{array}$ & $\begin{array}{c}\text { Laboratory Method }{ }^{\mathrm{c}} \\
\text { (Estimated or Published MDL) }\end{array}$ & Applicable WAC Limit \\
\hline Sulfide & NA & $\begin{array}{l}\text { SW-846 Method } 9030 \mathrm{~B}, 9031 \text { or } 9034 \\
(0.2 \mathrm{mg} / \mathrm{kg})\end{array}$ & ICDF Complex WAC: \\
\hline \multirow{3}{*}{ Cyanide } & \multirow{3}{*}{ NA } & \multirow{3}{*}{$\begin{array}{l}\text { SW-846 Method } 9010 \text { or } 9012 \\
(10 \mathrm{mg} / \mathrm{kg})\end{array}$} & $33,000 \mathrm{mg} / \mathrm{kg}$ \\
\hline & & & $\begin{array}{l}40 \text { CFR 268.49, Alternative Soil } \\
\text { Treatment Standards: }\end{array}$ \\
\hline & & & $300 \mathrm{mg} / \mathrm{kg}$ \\
\hline \multicolumn{4}{|l|}{ Radionuclides: } \\
\hline $\mathrm{TRU}^{\mathrm{m}}$ & NA & $\begin{array}{l}\text { Gross Spectrometric Alpha }{ }^{\mathrm{n}} \\
(5 \mathrm{pCi} / \mathrm{g})\end{array}$ & $\begin{array}{l}\text { ICDF Complex WAC: } \\
10 \mathrm{nCi} / \mathrm{g}\end{array}$ \\
\hline $\mathrm{Pu}-238$ & NA & $\begin{array}{l}\text { Radiochemistry and Alpha } \\
\text { Spectroscopy }{ }^{\mathrm{n}} \\
(0.05 \mathrm{pCi} / \mathrm{g})\end{array}$ & $\begin{array}{l}\text { ICDF Complex WAC: } \\
10 \mathrm{nCi} / \mathrm{g}\end{array}$ \\
\hline
\end{tabular}

a. As identified on the waste profile.

b. Use of all on-Site analytical methods will follow the manufacturer's operating procedures and a project-specific technical procedure developed to ensure that the method detection limits (MDLs) determined prior to implementation of the method are routinely achieved.

c. Laboratories will be approved by the INL in accordance with applicable laboratory procurement procedures.

d. SW-846 (EPA 1999); TE-Thermal extraction equivalent or superior to SW-846 Method 8275A; GC — Gas chromatography; GC/MS— Gas chromatography mass spectrometry; NA-Not applicable or the published MDL is not $<20 \%$ the action level; ND-Not determined; $\mathrm{XRF}$ - $\mathrm{x}$-ray fluorescence.

e. The MDL for analytes determined using sample preparations and instrumentation employed at the ICDF (e.g., in a modular laboratory or in the field) will be determined in accordance with the procedures found in 40 CFR 136 Appendix B, "Definition and Procedure for the Determination of the Method Detection Limit," prior to implementation of the method. The method will only be applicable to an analyte if the MDL is $<20 \%$ the action level for that analyte.

f. MDLs for organic analytes are expressed as published, wet weight estimated quantitation limits (EQLs) that are typically 5-10 times higher than the MDL. Laboratories will report undetected results as dry weight EQLs. Therefore, the EQL reported by the laboratory will be higher than the value listed on this table for samples that contain moisture.

g. The lowest alternative treatment standard for volatile organic compound (VOC) indicated in the ICDF Design Inventory (EDF-ER-264) as being destined for disposal at the ICDF is $60 \mathrm{mg} / \mathrm{kg}$.

h. Estimated quantitation limits for semivolatile organics are analyte-dependent. Most are $0.66 \mathrm{mg} / \mathrm{kg}$, but those with either poorer extraction efficiency or tendency to break down in the analytical system have an EQL of $3.3 \mathrm{mg} / \mathrm{kg}$.

i. The lowest alternative treatment standards for semivolatile organic compound (SVOC) indicated in the ICDF Design Inventory (EDF-ER-264) as being destined for disposal at the ICDF are $1.3 \mathrm{mg} / \mathrm{kg}$ (kepone) and $18 \mathrm{mg} / \mathrm{kg}$ (dibenzo(g,h,i)perylene).

j. $\mathrm{PCBs}=$ polychlorinated biphenyls.

k. Method 6010B MDLs are based on published instrument detection limits and assume a 1.0-g soil sample with $0 \%$ moisture digested using an acid digestion procedure.

1. The alternative soil treatment Universal Treatment Standard action levels are expressed in $\mathrm{mg} / \mathrm{L}$ toxicity characteristic leaching procedure (TCLP). The action levels expressed in $\mathrm{mg} / \mathrm{kg}$ are based on these alternative Universal Treatment Standards and have been converted to $\mathrm{mg} / \mathrm{kg}$ by multiplying the action level by 20 . These $\mathrm{mg} / \mathrm{kg}$ concentrations are to be used to determine when $\mathrm{x}$-ray fluorescence (XRF) analyses could be used.

m. Key transuranic (TRU) parameters are defined as alpha-emitting radionuclides with $\mathrm{t}^{1} \mathrm{2}>20$ yr (i.e., Np-237, $\mathrm{Pu}-238, \mathrm{Pu}-239, \mathrm{Pu}-242$,

Pu-244, Am-241, Am-243, Cm-243, Cm-245, Cm-246, Cm-248, Cm-250, Bk-247, Cf-249, Cf-251).

n. Refer to ER-SOW-394 for use of this method. 
The analyses will be performed in a laboratory using the SW-846 preparation Methods 5021 or 5035 (EPA 1999) followed by the gas chromatography mass spectrometry (GC/MS) Method 8260B or, at the ICDF, using an alternative method that meets the required detection sensitivity. Examples of alternative methods that may be used include:

- A thermal desorber extraction method equivalent or superior to SW-846 Method 8275A

- A headspace equilibrium technique equivalent or superior to SW-846 Method 5021

- $\quad$ A heated purge and trap technique equivalent or superior to SW-846 Method 5035.

Any of the three alternative methods must be followed by analysis on a gas chromatography (GC) instrument using a standard operating procedure developed for that instrument (e.g., EPA SOP 2110 [EPA 1999]).

A-1.2.1.2 Semivolatile Organics. Applicable SVOCs must be measured in soil destined for disposal at the landfill if an SVOC that is subject to the alternative LDR treatment standards for contaminated soils found in 40 CFR 268.49 is present. The measurements will be performed in a laboratory using SW-846 (EPA 1999) Method 3541 or 3550B and 8270C for most of the SVOCs of interest, SW-846 Method 3541 or 3550B and 8082 for polychlorinated biphenyls (PCBs), SW-846 Method 3541 or $3550 \mathrm{~B}$ and 8081 for kepone, or at the INL using an alternative method that meets the required detection sensitivity. Examples of alternative methods that may be used include:

- An immunoassay method such as SW-846 4020 (PCBs only)

- $\quad$ An electrochemical method such as SW-846 9078 (PCBs only)

- A thermal desorber extraction method equivalent or superior to SW-846 Method 8275A (SVOCs only)

- A traditional solvent extraction method like SW-846 Method 3541 (Automated Soxhlet Extraction) or 3550B (Sonication Extract) followed by analysis on either a GC or GC/MS instrument.

A-1.2.1.3 Inorganics. Applicable inorganic constituents must be measured in soil destined for disposal at the landfill if an inorganic constituent that is subject to the alternative LDR treatment standards for contaminated soils found in 40 CFR 268.49 is present. Characterization of metal constituents will be completed by performing analyses in either an off-Site laboratory or at the INL, as indicated in Table A-1.

The other regulated inorganic constituents, which have an applicable alternative LDR treatment standard for contaminated soils found in 40 CFR 268.49, are cyanides. As required by the regulation, cyanides will be determined using SW-846 Method 9010 or 9012 (EPA 1999) using a sample size of $10 \mathrm{~g}$ and a distillation time of 1 hour and 15 minutes.

\section{A-1.2.2 Methods Applicable to Determining Key Landfill Contaminants of Concern Parameters}

The following sections describe the analytical methods that will be used for various parameter classifications.

A-1.2.2.1 Toluene. Toluene must be measured in soil being disposed of in the landfill if it is potentially present at a concentration estimated at $\geq 20 \mathrm{mg} / \mathrm{kg}$. The analyses will be performed in a laboratory using the SW-846 preparation Methods 5021 or 5035 (EPA 1999) followed by the GC/MS 
Method $8260 \mathrm{~B}$ or at the ICDF using an alternative method that meets the required detection sensitivity. Examples of alternative methods that may be used include:

- A thermal desorber extraction method equivalent or superior to SW-846 Method 8275A

- A headspace equilibrium technique equivalent or superior to SW-846 Method 5021

- $\quad$ A heated purge and trap technique equivalent or superior to SW-846 Method 5035.

Any of the alternative methods must be followed by analysis on an instrument using a standard operating procedure developed for that instrument (e.g., EPA SOP 2110 [EPA 1999]).

A-1.2.2.2 Inorganics. Applicable inorganic constituents must be measured in soil disposed of in the landfill if an inorganic constituent listed in Appendix B, Table B-1, is expected to be present. Methods with appropriate sensitivity for determining the inorganic constituents at concentrations below the action level will be used. The characterization for metals constituents will be completed by performing analyses in either an off-Site laboratory or at the INL, as indicated in Table B-1.

The other regulated inorganic constituent that is a key landfill contaminant of concern (COC) is sulfide. Sulfides will be determined using SW-846 Method 9030B, 9031, or 9034 (EPA 1999).

A-1.2.2.3 Radionuclides. Applicable radionuclides must be measured in soil destined for disposal at the landfill if a radionuclide is expected to be present at a concentration estimated at $\geq 80 \%$ of the applicable WAC concentration guideline listed in the applicable landfill WAC (DOE/ID-10881 [DOE-ID 2006b]). Samples will be taken for Pu-238, the radionuclide of interest, which will be determined using sample preparation and alpha spectrometry techniques in accordance with an INL-approved or standard DOE laboratory method in accordance with the quality assurance and quality control requirements listed in ER-SOW-394, "Idaho National Engineering and Environmental Laboratory Sample and Analysis Management Statement of Work for Analytical Services."

Refer to Section A-1.2.3 of this appendix for a discussion of the analytical methods applicable to determining transuranic (TRU) activity.

\section{A-1.2.3 Methods Applicable to Determining Verification of Transuranic Activity}

Applicable radionuclides must be measured in soil being disposed of in the landfill if presence of TRU radionuclides is expected. The radionuclides of interest are the TRU radionuclides (atomic number greater than 92) that are alpha-emitting isotopes with a half-life of greater than 20 years. The includes several radionuclides that (1) tend to be extremely minor contributors to total TRU activity; (2) are used as tracers in radiochemical methods for the most common TRU radionuclides (e.g., Am-243 and Pu-242), and (3) tend to have very common spectral energies (e.g., the $\mathrm{Cm}$ isotopes all have energies very close to Am-241) and/or for which common analytical methods have not been developed. Therefore, the testing of samples requiring determination of total TRU activity will be sent to the INL Radiation Measurements Laboratory for the gross spectrometric alpha analysis in accordance with the quality assurance and quality control requirements listed in ER-SOW-394. Gross spectrometric alpha is a specialized technique, appropriate for determination of total TRU activity and is only available at the INL Radiation Measurements Laboratory. 


\section{A-1.2.4 Detection Limits}

The detection limits for the analytical methods used will be dependent on the matrix of the sample and the analytical technique employed. The laboratories used to perform analyses will perform method detection limit (MDL) studies prior to implementation of the SW-846 Methods (EPA 1999) on waste samples. If analytical techniques other than those performed in a fixed laboratory using standard SW-846 methods for organic and inorganic constituents and INL-approved methods for radionuclides are used for analysis, MDL studies will be conducted prior to implementation of the method. The detection limits determined for these alternative methods must be $\leq 20 \%$ of the applicable action level for a given analyte in order to qualify as applicable for determination of that analyte. If the method does not meet this detection sensitivity, the samples must be sent to an off-Site laboratory capable of performing methods with adequately low detection limits. 


\section{A-2. SAMPLE CONTROL}

Strict sample control is required on every characterization event. Sample control ensures that unique sample identifiers are used for separate samples. It also ensures that documentation of sample collection information is such that a sampling event may be reconstructed at a later date. The following sections detail unique sample designation, sample handling (including shipping), and radiological screening of samples.

\section{A-2.1 Sample Identification Code}

All samples collected for waste analyses will be related to the waste stream. The sample locations will be recorded in the sample logbook to maintain a record of characterization. The sample numbers scheme will follow the scheme used by the generating site for characterization.

It is recommended that all samples have a unique sample number identifier to prevent any confusion with sample numbers. The first part of the sample number will be specific to the waste stream being sampled. The waste stream identification (ID) will be followed by an underscore. The next character of the sample ID will be a two-character set (e.g., 01, 02) to designate the sequential sample number for the waste stream, followed by a two-character set for designation of type of sample (e.g., $\mathrm{CH}$, FD). The last two characters refer to a particular analysis and bottle type as provided by Sample and Analysis Management (SAM) staff.

In this example, a soil sample collected in support of the WAG 4 Central Facilities Area (CFA) -04 remediation might be designated as CFA020037_03VEAB where (from left to right):

- $\quad$ CFA020037 designates the sample as being collected from a specific waste stream

- 03 designates the sequential sample number for the waste stream

- $\quad \mathrm{CH}$ designates the type of sample $(\mathrm{CH}=$ characterization, $\mathrm{FD}=$ field duplicate $)$

- $\quad \mathrm{AB}$ designates gross alpha/beta analysis.

\section{A-2.2 Sample Designation}

\section{A-2.2.1 General}

Sample information will be recorded in a sample field logbook for all samples collected. The following sections describe the sample information that should be recorded in the sample field logbook.

\section{A-2.2.2 Sample Description}

The sample description contains information related to individual sample characteristics. The information described in the remainder of this section will be recorded in the sample field logbook and on the sample container labels.

A-2.2.1 Sampling Activity. The sampling activity contains information related to the location of the response action. The sample number in its entirety will be used to link information from other sources (e.g., field data and analytical data) to the sampling location for data reporting, sample tracking, and completeness reporting. The unique sample number also will be used by the analytical laboratory (for those samples requiring off-Site laboratory analysis) to track and report analytical results. 
A-2.2.2 Sample Location. This is an approximate location from where the sample was taken.

A-2.2.2.3 Collection Type. This is information concerning the type of sample collected (e.g., grab sample).

A-2.2.2.4 Sample Date. The sample date is essential information due to sample holding times.

\section{A-2.3 Sample Handling and Analysis}

Samples requiring laboratory analysis will be collected in pre-cleaned containers and packaged according to American Society for Testing and Materials, or EPA-recommended procedures.

\section{A-2.3.1 Sample Preservation}

Soil samples taken and analyzed on-Site do not require preservation if the analyses are performed immediately or in situ. Samples collected for later preparation and analysis for organic constituents and metals when mercury analysis is required will be preserved at $4^{\circ} \mathrm{C} \pm 2^{\circ} \mathrm{C}$. Samples collected for the analysis of radionuclides do not require preservation. All samples sent to contracted laboratories will be preserved prior to analysis as indicated in the analytical laboratory Statement of Work (SOW).

\section{A-2.3.2 Chain-of-Custody Procedures}

Sample containers will be stored in a secured area accessible only to the field team members. The chain-of-custody procedures specified in the QAPjP (DOE/ID-10587 [DOE-ID 2006a]) will be followed for all analytical laboratory samples. Chain-of-custody procedures are not applicable to those samples analyzed using on-Site methods since the samples are either analyzed immediately or in situ, or are always in a secure location after initial custody is secured (i.e., custody is never transferred).

\section{A-2.3.3 Transportation of Samples}

Samples requiring analysis by off-Site analytical laboratories will be shipped in accordance with the regulations issued by the Department of Transportation (DOT) (49 CFR 171-178) and EPA sample handling, packaging, and shipping methods (40 CFR 262, "Standards Applicable to Generators of Hazardous Waste").

A-2.3.3.1 Custody Seals. Custody seals will be placed on all shipping containers in such a way as to ensure that tampering or unauthorized opening does not compromise sample integrity. Clear plastic tape will be placed over the seals to ensure that the seals are not damaged during shipment.

A-2.3.3.2 On-Site and Off-Site Shipping. An on-Site shipment is any transfer of material within the perimeter of the INL. Site-specific requirements for transporting samples within INL boundaries and those required by the shipping and receiving department will be followed. Shipment within the INL boundaries will conform to DOT requirements as stated in 49 CFR Parts 171-178. Off-Site shipments will conform to all applicable DOT requirements.

\section{A-2.3.4 Sample Analysis}

The INL will prepare a Task Order Statement of Work (TOS) for laboratory services for the required analyses that will be conducted at a location other than the ICDF. For characterization sampling, the only required field quality control samples will be duplicates. These samples also will be included in the TOS. 
All samples will be collected and shipped, if required, in accordance with the QAPjP (DOE/ID-10587 [DOE-ID 2006a]). Laboratories approved by the INL in accordance with applicable laboratory procurement procedures will perform all off-Site laboratory sample analysis. The INL-approved laboratories will perform the analyses in accordance with all applicable SOWs and TOSs. Any unused sample residues that do not specifically need to be retained temporarily at the laboratory for characterization purposes must be disposed of by the off-Site laboratories as waste generated by them and as required by 40 CFR 300.440(a)(5), "Procedures for Planning and Implementing Off-Site Response Actions." The only exception provided by rule is if the U.S. Department of Energy Idaho Operations Office remedial project manager (a) determines that there is a need for the INL to return the specific residues to the INL Site for disposal in the ICDF, (b) ensures the proper management of the returned residues, and (c) gives specific written permission for the return of the sample residues.

All field analytical measurements will be performed in accordance with manufacturer's operating procedures and published methods or technical procedures developed to support the specific analysis being performed.

\section{A-2.4 Radiological Screening}

If samples are to be removed from the area and shipped or delivered to a laboratory, the samples will be surveyed for external contamination and radiation levels. If necessary, a gamma-screening sample will be collected and submitted to an on-Site analytical laboratory for a 20-minute analysis before

shipment off-Site. The field radiological control technician will determine the need for gamma screening. 


\section{A-3. PROJECT QUALITY OBJECTIVES}

The project quality objectives specify the measurements that must be met to produce acceptable data for a project. The technical and statistical qualities of these measurements must be properly documented. Precision, accuracy, and completeness are quantitative parameters that must be specified for physical/chemical measurements. Comparability and representativeness are qualitative parameters.

The project quality objectives will be met through a combination of field and laboratory checks. Field checks will consist of collecting field duplicates. For those samples requiring off-Site laboratory analysis, laboratory checks consist of initial and continuing calibration samples, laboratory control samples, matrix spikes, and matrix spike duplicates. Laboratory quality assurance is detailed in the QAPjP (DOE/ID-10587 [DOE-ID 2006a]).

Data associated with the waste samples will be obtained from various methods, depending on the contaminant and the specific characterization requirements. Recommended methods are listed in Table A-1 and include on-Site analysis and off-Site laboratory analysis. The project quality objectives will be addressed separately for the results from on-Site analytical methods and those from an outside analytical laboratory, due to the different analytical requirements associated with the methods.

\section{A-3.1 Quality Objective Parameters}

\section{A-3.1.1 Field Precision}

Field precision is a measure of the variability not due to laboratory or analytical methods. The three types of field variability or heterogeneity are spatially within a data population, between individual samples, and within an individual sample. Although the heterogeneity between and within samples can be evaluated using duplicate and/or sample splits, overall field precision will be calculated as the relative percent difference between two measurements, or relative standard deviation between three or more measurements. The relative percent difference or relative standard deviation will be calculated as indicated in the QAPjP (DOE/ID-10587 [DOE-ID 2006a]) for duplicate samples. To account for the uncertainty in radiological measurements, the mean difference will be calculated. For the results obtained from an outside analytical laboratory, the relative percent differences for inorganic and organic parameters are calculated by the laboratory and are indicated on quality control data reporting forms. For results from on-Site analytical methods, relative percent difference will be calculated from the duplicate results and will be recorded in the appropriate logbook. Mean differences for radiological parameters from either on-Site or off-Site methods will be calculated and recorded in the appropriate logbook.

\section{A-3.1.2 Field Accuracy}

Accuracy of field instrumentation will be maintained by calibrating all instruments used to collect data. Accuracy of laboratory measurements will be determined by following prescribed analytical methods and performing the required project quality analyses for the specified method. Accuracy can be measured through the use of surrogate spikes (organic analyses), matrix spikes, laboratory control samples, and performance evaluation sample materials. The use of surrogate spikes and matrix spikes are an inherent part of some of the analytical methods that will be used for characterization measurements. Performance evaluation sample materials will not be routinely used, but performance samples of INL soil matrix that have been used by the Radiological Environmental Sciences Laboratory for the Department of Energy Mixed Analyte Performance Evaluation Program may be used as a laboratory control sample material for measurements performed using x-ray fluorescence (XRF) at the ICDF. 


\section{A-3.1.3 Representativeness}

Representativeness is a qualitative parameter that expresses the degree to which the sampling and analysis data accurately and precisely represent the population parameter that drives an action to be taken. In essence, representativeness is a qualitative parameter that addresses whether the sampling program was properly designed to meet the DQOs. Representativeness will be evaluated by determining whether measurements are made and physical samples are collected in such a manner that the resulting data appropriately approximate the population parameter of interest. Confirming that sampling locations are selected properly and a sufficient number of samples are collected to meet the requirements stated in the DQOs are the best ways to evaluate the representativeness criterion.

\section{A-3.1.4 Comparability}

Comparability is a qualitative characteristic that refers to the confidence with which one data set can be compared to another. For the characterization samples, results from within a given waste stream will be compared to a maximum concentration obtained from previous studies. At a minimum, comparable data must be obtained using unbiased sampling designs. Data comparability will be assessed through the comparison of all data sets collected for the particular waste stream being sampled using the following parameters:

- Units will be expressed in common metrics

- Analytical procedures with appropriately low detection limits relative to the action level will be used to collect data for a given contaminant

- $\quad$ Standard methods of sample collection and handling will be followed

- $\quad$ Methods chosen for analysis may vary for a given analyte, but care will be taken to ensure that detection limits for the analyte are sufficiently low, regardless of the method chosen, to make comparable decisions relative to the action level

- Samples within data sets will be selected in a similar manner.

\section{A-3.1.5 Completeness}

Completeness is a measure of the quantity of usable data collected during the field sampling activities. The QAPjP (DOE/ID-10587 [DOE-ID 2006a]) requires that an overall completeness goal of $90 \%$ must be achieved for noncritical samples. If critical parameters or samples are identified, a 100\% completeness goal is specified. Critical data points are those sample locations or parameters for which valid data must be obtained for the sampling event to be considered complete.

Field completeness will be assessed by comparing the number of samples collected to the number of samples planned. Field sampling completeness is affected by such factors as equipment and instrument malfunctions and insufficient sample recovery. Completeness will be assessed following data validation and reduction.

Because of the critical nature of the data being collected in support of the characterization sampling, the completeness goal for the sampling efforts will be $100 \%$. 


\section{A-3.2 Field Data Reduction}

The reduction of field data is important to ensure that there have been no errors in sample labeling and documentation. The sample team will review all field data for accuracy. This review includes cross-referencing the samples that are collected with sample labels, logbooks, and chain-of-custody forms, if required. Prior to sample shipment to the laboratory, or upon completion of daily sampling activities, field personnel will ensure that all field information is properly documented. Review of the sample field logbooks will be performed to ensure all required information is properly documented.

\section{A-3.3 Data Validation}

Method data validation is the process whereby analytical data are reviewed against set criteria to ensure that the results conform to the requirements of the analytical method and any other specified requirements. A cursory contractual compliance review of all laboratory data will be performed to ensure that contractual requirements have been met. This cursory review could include, but is not limited to, ensuring the following:

- $\quad$ The analytical laboratory performed the requested methods

- Holding times were met

- All required analytes were included in the calibration standards for the method

- $\quad$ All samples shipped were analyzed

- $\quad$ All quality control samples were run at the appropriate frequency.

Field-generated data will be validated by periodic reviews of data to ensure proper calibration of the instrument and other data collection activities were appropriately documented in a bound sample or field logbook. The quality of field-generated data will be ensured through adherence to the manufacturer's operating procedures, conformance to any specific technical procedures prepared for the analyses conducted, and use of equipment calibration, as appropriate. 


\section{A-4. DATA MANAGEMENT/DATA ANALYSIS AND UNUSUAL OCCURRENCES}

All samples will be recorded in the appropriate sample field logbook. Analytical results, taken on-Site using methods specified in Table A-1, will also be recorded in the appropriate sample field logbook. If an on-Site analytical method produces a printed analytical report, the report will be retained in the project file. If the field instrument requires quality control checks, calibrations, etc., this information will be saved and placed in the project file.

Analytical results obtained from an off-Site analytical laboratory will be managed and maintained by the INL in accordance with applicable procedures.

This section discusses the approach to managing the data, analysis of data, and suggested responses to unusual occurrences associated with characterization sample data.

\section{A-4.1 Data Management}

The following sections present the processes associated with managing the data collected for characterization samples.

\section{A-4.1.1 On-Site Analytical Data}

On-Site analytical sample data will be managed, tracked, and maintained by the waste generator and maintained in accordance with approved procedures. Since on-Site analytical sample data result from field instrumentation, standard company procedures for data validation are not applicable.

\section{A-4.1.2 Off-Site Laboratory Analytical Data}

Off-Site laboratory analytical samples and related data will be managed and maintained by the INL in order to ensure an efficient and accurate means of sample and data tracking.

INL samplers will be responsible for taking the sample, preparing the sample shipment, and shipping the sample to the analytical laboratory. The INL will begin tracking analytical laboratory sample data once the samples are shipped to the INL-contracted laboratory. Laboratory compliance includes adherence to sample holding times, requested analytical methods, and data deliverables. When the laboratory analytical data package, or sample delivery group, is received from the laboratory, cursory technical reviews on the data packages are performed to assess the completeness and technical compliance with respect to the project's analysis-specific TOS or SOW. Errors in a data package will be resolved among ICDF project personnel, the INL chemist(s), the originating lab, and SAM.

\section{A-4.1.3 Field Data}

Field data taken in support of the laboratory analytical samples include all data that are nonchemical analytical data. These data will be managed by INL according to applicable procedures. 


\section{A-4.2 Data Analysis}

\section{A-4.2.1 On-Site Analytical Data}

On-Site analytical methods will be used to obtain analytical data results for some contaminant types. Analytical data resulting from on-Site methods will be reviewed by a qualified technician.

\section{A-4.2.2 Off-Site Laboratory Analytical Data}

A cursory contractual compliance review of all laboratory data will be performed to ensure that contractual requirements have been met.

\section{A-4.2.3 Field Data}

Field data will be analyzed using methods that are appropriate for the data types and specific field conditions. Analysis will include recognized methods and techniques that are used with the specific data types and may include statistical processes (e.g., instrument quality control checks).

\section{A-4.3 Unusual Occurrences}

Unusual occurrences are situations that are unforeseen, unanticipated, or unexpected. They may occur in chemical data sets or as field-related data and observations. An example of an unusual occurrence is detection of a contaminant where previously it was undetected, or an inability to obtain a required sample.

The following is meant to provide a process for resolving an unusual occurrence rather than a method for dealing with each specific unusual occurrence. The following steps will be taken to resolve an unusual occurrence:

- $\quad$ Record the unusual occurrence and supporting observations in the sample field logbook.

- $\quad$ Validate the unusual occurrence (e.g., reanalyze the sample if any remains) and report to the program manager as soon as possible.

- If the unusual occurrence is of a significant nature (significant is anything that can impact the decisions to be made with the characterization results), it will be reported to the appropriate ICDF personnel. Agency notification will only be made if the waste is improperly disposed of in the landfill.

- If the unusual occurrence is not of a significant nature (e.g., malfunctioning instrument), it will be resolved by the technical leader and is a nonissue. 


\section{A-5. REFERENCES}

40 CFR 136, Appendix B, 1999, "Definition and Procedure for the Determination of the Method Detection Limit," Rev. 1.11, Code of Federal Regulations, Office of the Federal Register, July 1999.

40 CFR 262, 1999, "Standards Applicable to Generators of Hazardous Waste," Code of Federal Regulations, Office of the Federal Register, July 1999.

40 CFR 268.49, 1999, “Alternative LDR Treatment Standards for Contaminated Soil," Code of Federal Regulations, Office of the Federal Register, July 1999.

40 CFR 300.440, 2006, "Procedures for Planning and Implementing Off-Site Response Actions," Code of Federal Regulations, Office of the Federal Register, August 2006.

49 CFR 171, 1999, "General Information, Regulations, and Definitions," Code of Federal Regulations, Office of the Federal Register, October 1999.

49 CFR 172, 1999, "Hazardous Materials Table, Special Provisions, Hazardous Materials Communications, Emergency Response Information, and Training Requirements," Code of Federal Regulations, Office of the Federal Register, October 1999.

49 CFR 173, 1999, "Shippers-General Requirements for Shipments and Packaging," Code of Federal Regulations, Office of the Federal Register, October 1999.

49 CFR 174, 1999, "Carriage By Rail," Code of Federal Regulations, Office of the Federal Register, October 1999.

49 CFR 175, 1999, "Carriage By Aircraft," Code of Federal Regulations, Office of the Federal Register, October 1999.

49 CFR 176, 1999, "Carriage By Vessel," Code of Federal Regulations, Office of the Federal Register, October 1999.

49 CFR 177, 1999, "Carriage By Public Highway," Code of Federal Regulations, Office of the Federal Register, October 1999.

49 CFR 178, 1999, "Specifications for Packaging," Code of Federal Regulations, Office of the Federal Register, October 1999.

DOE-ID, 2006a, Quality Assurance Project Plan for Waste Area Groups 1, 2, 3, 4, 5, 6, 7, 10, and Removal Actions, DOE/ID-10587, Rev. 9, U.S. Department of Energy Idaho Operations Office, July 2006.

DOE-ID, 2006b, ICDF Complex Waste Acceptance Criteria, DOE/ID-10881, Rev. 3, U.S. Department of Energy Idaho Operations Office, October 2006.

EDF-ER-264, 2004, “INEEL CERCLA Disposal Facility Design Inventory,” Rev. 2, Environmental Restoration Program, Idaho National Engineering and Environmental Laboratory, June 2004. 
EPA, 1999, "Test Methods for Evaluating Solid Waste, Physical/Chemical Methods," Third Edition, SW-846, U.S. Environmental Protection Agency, 1999.

ER-SOW-394, 2004, "Idaho National Engineering and Environmental Laboratory Sample and Analysis Management Statement of Work for Analytical Services," Rev. 2, Idaho National Engineering and Environmental Laboratory, May 2004. 


$$
\text { A-20 }
$$


Appendix B

Additional Waste Verification Sampling Guidance for Select Waste Streams 
B-2 


\section{Appendix B}

\section{Additional Waste Verification Sampling Guidance for Select Waste Streams}

\section{B-1. PURPOSE AND SCOPE}

Comprehensive Environmental Response, Compensation, and Liability Act (CERCLA) wastes generated within the boundaries of the Idaho National Laboratory (INL) are disposed of at the Idaho CERCLA Disposal Facility (ICDF). Waste acceptance at the ICDF is controlled through the implementation of Waste Acceptance Criteria (WAC) documentation that establishes numerical mass limits for constituents of concern.

The ICDF Complex Waste Profile and Verification Sample Guidance defines the process for collecting samples and performing waste characterization of waste streams proposed for acceptance at the ICDF. A key component of the waste acceptance process involves comparison of the analytical data against the WAC limits to ensure no waste stream is accepted into the facility that will result in the total mass of any given restricted constituent exceeding the landfill total mass limits.

If, during the waste acceptance review process, the mass of an individual constituent is present in a waste stream in excess of a pre-established percent of the available landfill limit for that constituent, additional sampling and analysis may be required to ensure the waste can be compliantly accepted into the ICDF. This document will provide the guidance for determining when such additional characterization is necessary and will define the process for performing the appropriate verification sampling.

\section{B-2. APPLICABILITY BASED ON SEVERITY OF CONTAMINATION}

Additional verification sampling is determined based on the total mass of specific constituents in a waste stream compared against the WAC mass limits for that constituent and the running total of the landfill inventory. Constituents that have limits based on regulatory limits or other concerns such as liner compatibility are considered key parameters and are identified on Table B-1. Any waste stream containing a key parameter with a total mass that exceeds $75 \%$ of the remaining landfill capacity for that parameter may be subject to the additional verification sampling defined in this guidance document. In addition, any other WAC-regulated constituent (non-key parameter) that is present in a waste stream with a total mass of $90 \%$ of the remaining landfill capacity for that constituent may also be subject to this additional sampling.

\section{B-3. SAMPLING REQUIREMENTS}

The required verification sampling will be performed under the direction of the ICDF waste specialist (or designee). The objective of the waste verification sampling is to provide additional assurance that the waste stream, if accepted for disposal into the ICDF, will not result in the ICDF landfill WAC mass limits being exceeded. 
Table B-1. ICDF key waste acceptance parameters.

\begin{tabular}{|c|c|c|c|}
\hline \multicolumn{4}{|c|}{ Organic Constituents } \\
\hline 1,1,1-Trichloroethane & $2,3,7,8-\mathrm{TCDF}$ & Anthracene & Ethylbenzene \\
\hline 1,1,2,2-Tetrachloroethane & 2,4,5-Trichlorophenol & Aramite & Famphur \\
\hline 1,1,2-Trichloroethane & 2,4,6-Trichlorophenol & Benzene & Fluoranthene \\
\hline 1,1-Dichloroethane & 2,4-Dichlorophenol & Benzo(a)anthracene & Fluorine \\
\hline 1,1-Dichloroethene & 2,4-Dimethylphenol & Benzo(a)pyrene & Hexachlorobenzene \\
\hline $1,2,3,4,6,7,8,9-\mathrm{OCDD}$ & 2,4-Dinitrophenol & Benzo(b)fluoranthene & Hexachlorobutadiene \\
\hline $1,2,3,4,6,7,8,9-\mathrm{OCDF}$ & 2,4-Dinitrotoluene & Benzo(g,h,i)perylene & Hexachlorocyclopentadiene \\
\hline $1,2,3,4,6,7,8-\mathrm{HpCDD}$ & 2,6-Dinitrotoluene & Benzo(k)fluoranthene & Hexachloroethane \\
\hline $1,2,3,4,6,7,8-\mathrm{HpCDF}$ & 2-Butanone & bis(2-Chloroethoxy)methane & Indeno(1,2,3-cd)pyrene \\
\hline $1,2,3,4,7,8,9-\mathrm{HpCDF}$ & 2-Chloronaphthalene & bis(2-Chloroethyl)ether & Isobutyl alcohol \\
\hline $1,2,3,4,7,8-\mathrm{HxCDD}$ & 2-Chlorophenol & bis(2-Chloroisopropyl)ether & Isopropyl alcohol/2-propanol \\
\hline $1,2,3,4,7,8-\mathrm{HxCDF}$ & 2-Methylphenol & bis(2-Ethylhexyl)phthalate & Kepone \\
\hline $1,2,3,6,7,8-\mathrm{HxCDD}$ & 2-Nitroaniline & Bromomethane & Methylene chloride \\
\hline $1,2,3,6,7,8-\mathrm{HxCDF}$ & 2-Nitrophenol & Butane,1,1,3,4-tetrachloro & Naphthalene \\
\hline $1,2,3,7,8,9-\mathrm{HxCDD}$ & 4,6-Dinitro-2-methylphenol & Butylbenzylphthalate & Nitrobenzene \\
\hline $1,2,3,7,8,9-\mathrm{HxCDF}$ & 4-Bromophenyl-phenylether & Carbon disulfide & N-Nitroso-di-n-propylamine \\
\hline 1,2,3,7,8-PeCDD & 4-Chloro-3-methylphenol & Chlorobenzene & N-Nitrosodiphenylamine \\
\hline $1,2,3,7,8-\mathrm{PeCDF}$ & 4-Chloroaniline & Chloroethane & Pentachlorophenol \\
\hline 1,2,4-Trichlorobenzene & 4-Methyl-2-pentanone & Chloromethane & Phenanthrene \\
\hline 1,2-Dichlorobenzene & 4-Nitroaniline & Chrysene & Phenol \\
\hline 1,2-Dichloroethane & 4-Nitrophenol & Dibenz(a,h)anthracene & Pyrene \\
\hline 1,3-Dichlorobenzene & Acenaphthene & Dichlorodifluoromethane & Tetrachloroethene \\
\hline 1,4-Dichlorobenzene & Acenaphthylene & Diethylphthalate & Toluene \\
\hline 1,4-Dioxane & Acetone & Dimethylphthalate & Trichloroethene \\
\hline $2,3,4,6,7,8-\mathrm{HxCDF}$ & Acetonitrile & Di-n-butylphthalate & Vinyl Chloride \\
\hline 2,3,4,7,8-PeCDF & Acrolein & Di-n-octylphthalate & Xylene (ortho) \\
\hline $2,3,7,8-\mathrm{TCDD}$ & Acrylonitrile & Ethyl cyanide & Xylene (total) \\
\hline \multicolumn{4}{|c|}{ Inorganic Constituents } \\
\hline Arsenic & Chromium & Manganese & Sulfide \\
\hline Barium & Cobalt & Mercury & Thallium \\
\hline Beryllium & Cyanide & Nickel & Vanadium \\
\hline Boron & Fluoride & Selenium & Zinc \\
\hline Cadmium & Lead & Silver & \\
\hline \multicolumn{4}{|c|}{ Radiological Constituents } \\
\hline Cs-137 & $\mathrm{I}-129$ & Pu-238 & Total TRU $\geq 10 \mathrm{nCi} / \mathrm{g}$ \\
\hline
\end{tabular}

\section{B-3.1 Sample Size}

Using the guidance provided in EPA (2002) on exceedance rules, the number of samples required for waste verification can be determined. The simple exceedance rule provides specified confidence (1- $\alpha)$ that a percent $(p)$ of the data fall below the limit and does not require that any assumptions be made about the distribution of the data. If the maximum verification sample result is used to compare to the Material 
Profile for a specified confidence and percent, the required sample size (n) can be determined using the following equation found in (EPA 2002).

$$
n=\frac{\log (\alpha)}{\log (p)}
$$

The simple exceedance rule will be applied to lots of (at most) 5,000 $\mathrm{yd}^{3}$. There may be more than one lot from a single waste stream or there may be a waste stream with only one lot having volume at most $5,000 \mathrm{yd}^{3}$. The population units within each lot are defined to be a maximum of $50 \mathrm{yd}^{3}$ and a minimum of $15 \mathrm{yd}^{3}$. These population unit sizes are based on homogeneous waste from a given waste stream. Only one sample will be collected from any given population unit so that sample size may be limited by a small lot volume. The sample size for specified confidence and percent is specified for each lot within a waste stream. Also, the decision to pass or fail verification is made on a lot-by-lot basis.

The required confidence and percent for the simple exceedance rule will depend on the mass of the parameter in the waste with regard to the applicable WAC mass limit and the mass of the parameter already disposed of in the landfill (Table B-2). The confidence and percent will be greater for waste with concentrations closer to the applicable limit, based on the cutoff limits of $75 \%$ and $90 \%$ for key parameters identified in Table B-1, and 90\% for all landfill WAC-regulated parameters. For waste with key parameter concentrations $\geq 70 \%$ and $<90 \%$, there will be $90 \%$ confidence in the 90 th percentile. For wastes with parameter concentrations $\geq 90 \%$, there will be $95 \%$ confidence in the 95 th percentile. The sample sizes required for these percentiles and confidence levels are contained in Table B-2.

The sample sizes in Table B-2 are based on the assumption that all verification sample results must be below the maximum concentration specified on the Material Profile. Greater sample sizes will result if the decision rule allows one verification sample result to exceed the concentrations specified on the Material Profile. These sample sizes can be determined using tables in Appendix G of EPA (2002).

Table B-2. Sample sizes for simple exceedance rule.

\begin{tabular}{|c|c|c|c|}
\hline $\begin{array}{c}\text { Concentration of Key } \\
\text { Parameter as Percent } \\
\text { of Applicable Limit }\end{array}$ & $\begin{array}{l}\text { Percent } \\
(p)\end{array}$ & $\begin{array}{l}\text { Verification } \\
\text { Confidence } \\
\quad(1-\alpha)\end{array}$ & $\begin{array}{c}\text { Total Verification } \\
\text { Sample Size for } \\
\text { a Given Lot }\end{array}$ \\
\hline$\geq 70 \%$ and $<90 \%$ & 0.90 & 0.90 & 22 \\
\hline$\geq 90 \%$ & 0.95 & 0.95 & 59 \\
\hline \multicolumn{4}{|c|}{ a. Lot sample size based on a maximum volume of $5,000 \mathrm{yd}^{3}$. } \\
\hline \multicolumn{4}{|c|}{$\begin{array}{l}\text { b. A maximum of one sample per population unit will be taken. The maximum size of a population unit will be } 50 \mathrm{yd}^{3} \text {; the } \\
\text { minimum size of a population unit will be } 15 \mathrm{yd}^{3} \text {. }\end{array}$} \\
\hline
\end{tabular}

\section{B-3.2 Sample Selection}

Figure B-1 presents the verification sampling process flow. Verification sample selection will be flexible to accommodate in situ waste and waste that is or will be containerized prior to verification sampling. However, for each waste stream subject to additional verification sampling, verification sampling requirements will follow one approach; a mixture of in situ and container sampling approaches will not be allowed for a single waste stream. 


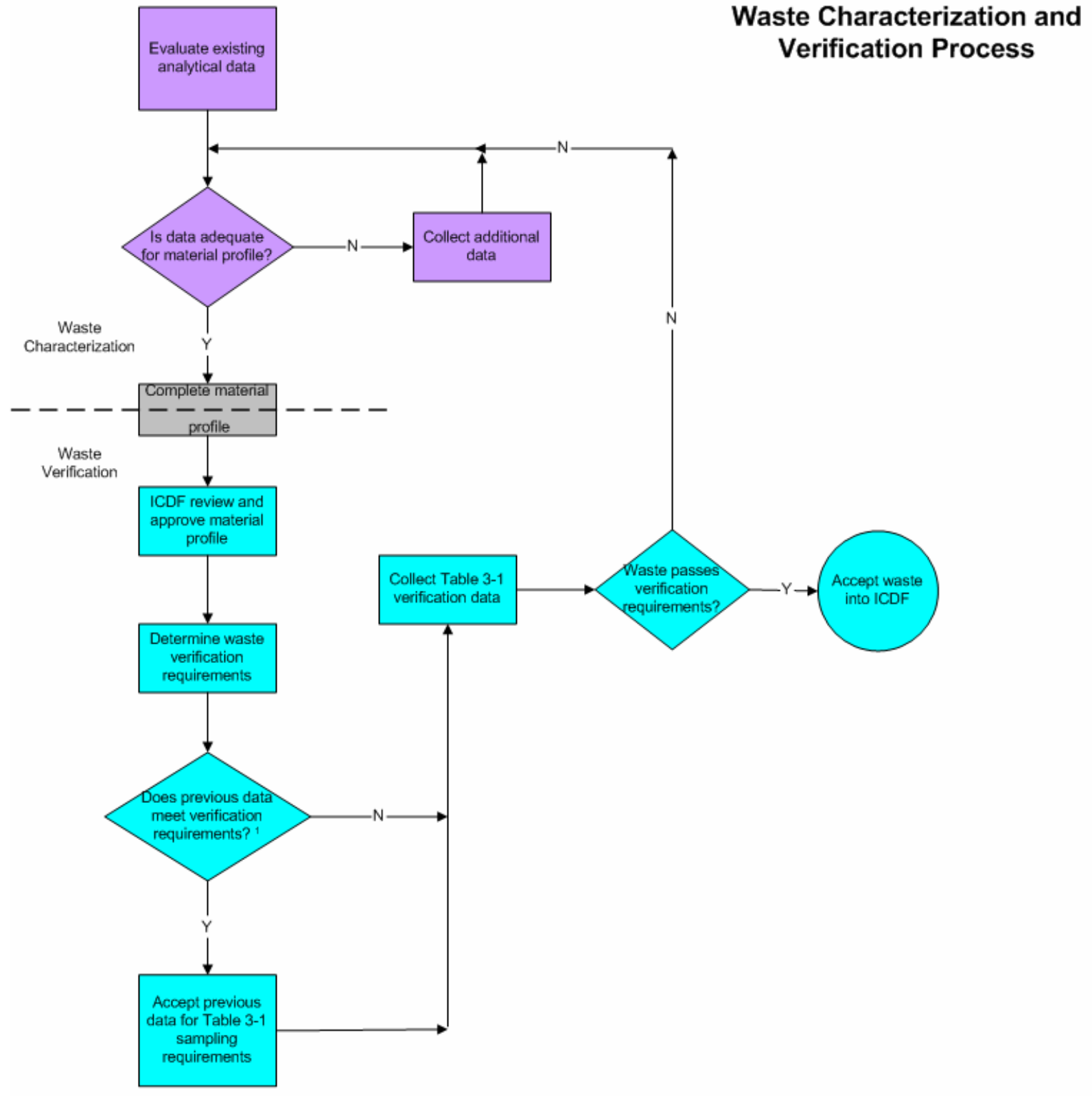

1. Verification Data will be independent of the characterization data.

Figure B-1. Verification process flow. 
All verification samples will be taken under the direction of the ICDF waste acceptance personnel. Therefore, verification sample selection for a given waste stream will be independent of any effort by the waste generator to select characterization samples used to complete the Material Profile.

For sampling in situ waste, the volume of waste will be divided into lots of size no more than $5,000 \mathrm{yd}^{3}$ and the population unit will be a maximum of $50 \mathrm{yd}^{3}$. If the lot size is less than $5,000 \mathrm{yd}^{3}$, then the lot will be divided into approximately 100 population units, with a minimum population unit size of $15 \mathrm{yd}^{3}$. After being divided into lots, a three-dimensional grid of specified population unit size will be overlain. The required number of samples will be selected from randomly chosen grid cells. Using this approach, data from previously collected samples that fall within randomly selected grid cells can be used if they were collected and analyzed using comparable methods and are recent enough so that temporal change is not an issue. It is expected that only a few waste generators will have previously collected sample data meeting these criteria.

For sites where in situ waste verification sampling will not be performed prior to excavation, a grid will not be utilized. Rather, a random sample of containers within a lot will be chosen. (A lot being no more than $5,000 \mathrm{yd}^{3}$ and a population unit size being at least $15 \mathrm{yd}^{3}$.) This applies to waste that is or will be containerized prior to verification sampling. If a previously collected sample is available from that container and it was collected and analyzed using comparable methods and is recent enough so that temporal change is not an issue, it can be utilized for verification of containerized waste.

All verification samples will be required to be representative of the waste in a given population unit. As such, properties of the contaminant of concern (COC) must be taken into account in order to represent the concentration of the COC in the sample (e.g., for previously containerized waste, an auger sample would be taken if any question of homogeneity in that population unit existed). All samples will be collected following EPA-approved sampling methods.

For waste streams larger than $5,000 \mathrm{yd}^{3}$, the waste stream will be divided into approximately equal size lots as close to $5,000 \mathrm{yd}^{3}$ as possible. This will be performed in order to allocate samples evenly among lots within one waste stream and to maintain a constant population unit size for a waste stream. For example, a waste stream of 7,000 $\mathrm{yd}^{3}$ would be divided into two lots of 3,500 $\mathrm{yd}^{3}$ instead of one lot of $5,000 \mathrm{yd}^{3}$ and one lot of $2,000 \mathrm{yd}^{3}$.

If the waste stream is small enough that approximately 100 population units do not exist (i.e., the waste stream is less than $1,500 \mathrm{yd}^{3}$ ), then the required number of verification samples will be taken from the available population units. If the number of available population units is equal to or less than the required number of verification samples, then each population unit will be sampled.

\section{B-3.3 Analytical Method Requirements}

Recommended analytical methods to be used for verification samples are addressed in Section 4.1 of the ICDF Complex Waste Profile and Verification Sample Guidance (i.e., the main text of this document). The methods used will depend on the parameter of interest and the detection level required to meet the appropriate percent of the applicable limits. 


\section{B-4. ASSESSMENT OF VERIFICATION RESULTS}

The results of the verification sampling will be used to determine whether significant mass levels of specific constituents can be compliantly accepted into the landfill. Waste acceptance is performed on a case-by-case basis. When the $75 \%$ and $90 \%$ mass limits are reached, waste shipments may be received at the ICDF facility for staging or storage but will not be disposed of until the verification sample results have been validated to ensure the mass limits on the landfill are not exceeded.

\section{B-5. REFERENCES}

EPA, 2002, RCRA Waste Sampling Draft Technical Guidance, Planning, Implementation, and Assessment, U.S. Environmental Protection Agency, Office of Solid Waste and Emergency Response EPA 530-D-02-002, August 2002. 